Old Dominion University

ODU Digital Commons

1983

\title{
Low-Frequency Current and Temperature Variability From Gulf Stream Frontal Eddies and Atmospheric Forcing Along the Southeast U.S. Outer Continental Shelf
}

\author{
Thomas N. Lee \\ Larry P. Atkinson \\ latkinso@odu.edu
}

Follow this and additional works at: https://digitalcommons.odu.edu/ccpo_pubs

Part of the Oceanography Commons

\section{Original Publication Citation}

Lee, T. N., \& Atkinson, L. P. (1983). Low-frequency current and temperature variability from Gulf Stream frontal eddies and atmospheric forcing along the southeast US outer continental shelf. Journal of Geophysical Research: Oceans, 88(C8), 4541-4567. doi:10.1029/JC088iC08p04541| 


\title{
Low-Frequency Current and Temperature Variability From Gulf Stream Frontal Eddies and Atmospheric Forcing Along the Southeast U.S. Outer Continental Shelf
}

\author{
Thomas N. LeE \\ School of Marine and Atmospheric Science, Division of Meteorology and Physical Oceanography, University of Miami \\ Miami, Florida 33149
}

LARRY P. AtKInson

Skidaway Institute of Oceanography, Skidaway Island, Savannah, Georgia 31406

\begin{abstract}
Low-frequency current and temperature time series from the outer shelf between Cape Canaveral, Florida, and Cape Romain, South Carolina, are compared with shipboard hydrographic data, satellite VHRR, coastal and buoy winds, and coastal sea level during the period from February to June 1980. Low-frequency current and temperature variability along the shelf break was primarily produced by cyclonic, cold core Gulf Stream frontal eddies. These disturbances traveled to the north at speeds of $\mathbf{5 0}$ to $70 \mathrm{~cm} \mathrm{~s}^{-1}$ with periods of 5 to 9 days throughout the experiment and produced cold cyclonic perturbations of the northward mean flow and temperature fields over an along-shelf coherence scale of $100 \mathrm{~km}$. Frontal eddies appear to be an important mechanism in the observed eastward transport of northward momentum and heat along the shelf edge. They also appear to play a key role in the transfer of eddy kinetic and potential energy back to the mean flow, which suggests an upstream formation region and shear-induced dissipation. Upwelling velocities of about $10^{-2} \mathrm{~cm} \mathrm{~s}^{-1}$ in the cold core provide the major source of new nutrients to the outer shelf. Subtidal flow variability at the $40-\mathrm{m}$ isobath was a mixed response to Gulf Stream and wind forcing. Barotropic along-shelf current oscillations were coherent with the local winds and coastal sea level at periods of 3-4 and 10-12 days over along-shelf scales of $400 \mathrm{~km}$ with small phase lags, suggesting a nearly simultaneous frictional equilibrium response to coherent wind-induced sea level slopes.
\end{abstract}

\section{INTRODUCTION}

The low-frequency current and temperature response to wind and Gulf Stream forcing in the southeast U.S. outer continental shelf has been investigated using moored current meter, hydrographic, wind, and satellite VHRR data collected as part of a Department of Energy and Bureau of Land Management supported interdisciplinary study of the region.

Shelf topography is particularly simple along the southeast United States, consisting of a broad shallow shelf that slopes gently to a rather sharp shelf break at about the 75-m depth (Figure 1). Shelf widths vary from a minimum of about $50 \mathrm{~km}$ off Cape Canaveral to a maximum of $120 \mathrm{~km}$ off Brunswick and Savannah, Georgia. Isobaths tend to follow the slight cuspate shape of the coast with diverging isobaths north of Cape Canaveral and convergence at Cape Romain. A shallow shoal extending from Cape Fear forms the northern boundary of the region and has considerable influence over the flow in that region (L. J. Pietrafesa, unpublished report, 1981). East of Savannah a topographic anomaly of the slope known as the 'Charleston Bump' [Brooks and Bane, 1978] protrudes into the Gulf Stream.

Previous investigations indicate that the shelf can be subdivided into three cross-shelf zones according to the physics controlling the low-frequency flow variability [Atkinson et al., this issue]. Waters in the inner shelf $(0-20 \mathrm{~m})$ are influenced by density effects from river runoff which tends to form a band of low-salinity, stratified waters near the coast [Blanton, 1980]. Bumpus [1973] found evidence of persistent southward flow

Copyright 1983 by the American Geophysical Union.

Paper number $2 \mathrm{C} 0942$.

0148-0227/83/002C-0942\$05.00 from surface drifter trajectories in this band. Local wind forcing and seasonal atmospheric changes are also influential in this region. In the midshelf zone ( $21-40 \mathrm{~m}$ ), subtidal flow variability has been observed to be strongly related to local wind forcing in the 2-day to 2-week period band [Lee and Brooks, 1979; Klinck et al., 1981] through a frictional equilibrium process similar to that observed in the Mid-Atlantic Bight [Beardsley and Butman, 1974; Scott and Csanady, 1976]. This region undergoes a seasonal change in stratification with vertically well mixed conditions characteristic of fall and winter and vertically stratified conditions occurring during spring and summer [Atkinson et al., this issue]. Low-frequency flow variability and water exchange in the outer shelf $(41-75 \mathrm{~m})$ have been shown to be primarily produced by Gulf Stream frontal disturbances such as northward propagating wavelike meanders and cold cyclonic frontal eddies, which occur on time scales of 2 days to 2 weeks [Lee and Brooks, 1979; Lee et al., 1981]. South of $32^{\circ} \mathrm{N}$ the western edge of the Gulf Stream generally lies within \pm 15 $\mathrm{km}$ of the shelf break [Bane and Brooks, 1979]. Frontal eddies have been shown to propagate along the outer shelf in this region, causing an exchange of water and momentum and a net flux of nutrients to the shelf [Lee et al., 1981]. Yoder et al. [1981] found a significant phytoplankton response to upwelling in the cold core of frontal eddies. Between $32^{\circ}$ and $33^{\circ} \mathrm{N}$ the 'Charleston Bump' appears to force an offshore meander of the Gulf Stream [Brooks and Bane, 1978; Pietrafesa et al., 1978; Legeckis, 1979]. Downstream of the 'Bump,' enlarged wavelike meanders can displace the Gulf Stream front up to $100 \mathrm{~km}$ from the shelf break [Legeckis, 1979; Bane and Brooks, 1979]. These enlarged 'meanders' have similar kinematic properties [Brooks and Bane, 1981; Bane et al., 1981] as those observed in the smaller frontal eddies off the Georgia shelf and suggest a dynamic connection. 


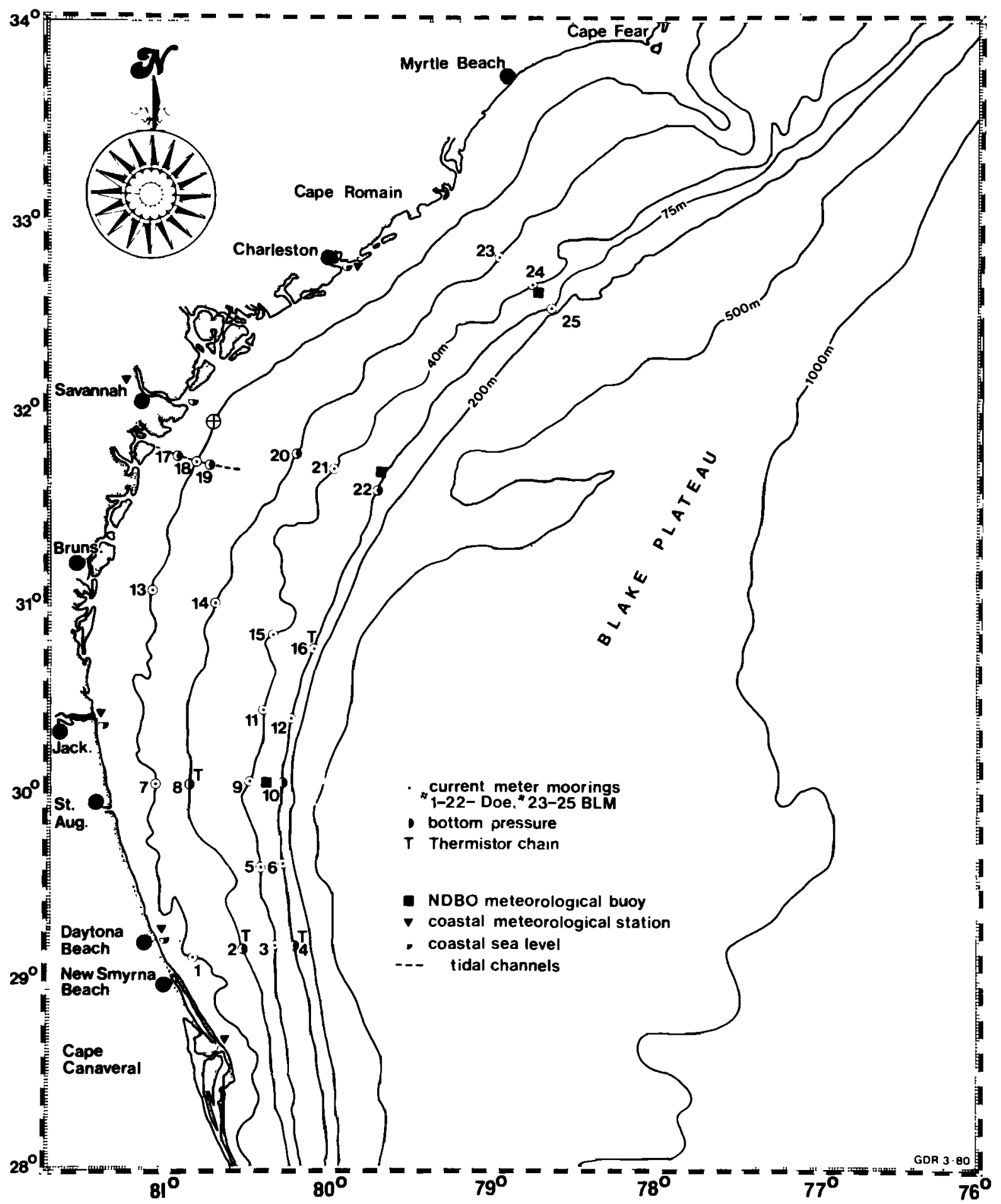

Fig. 1. GABEX 1 subsurface current meter array, February 17 to June 26, 1980.

During the winter/spring of 1980 a multi-institutional study of physical, chemical, and biological processes on the southeast U.S. shelf was undertaken. The University of Miami effort involved moored current meter measurements along the 40 and 75-m isobaths (outer shelf) from Savannah, Georgia, to New Smyrna Beach, Florida. North Carolina State University was responsible for the midshelf and inner shelf moorings in this region, and Science Applications, Inc., was responsible for the moorings off Cape Romain. In this paper we present findings from the outer shelf.

\section{Observational Methods}

Seven cross-shelf pairs of subsurface, taut wire current meter moorings were deployed on the 40- and 75- $\mathrm{m}$ isobaths between Cape Canaveral, Florida, and Cape Romain, South Carolina, for a 4-month period from February 16 to July 2, 1980 (Figure 1). The array was designed to investigate the effects of propagating Gulf Stream frontal disturbances on shelf processes over a wide range of spatial scales. Standard Aanderaa current meters were deployed at depths of 17,45 , and $72 \mathrm{~m}$ on most of 


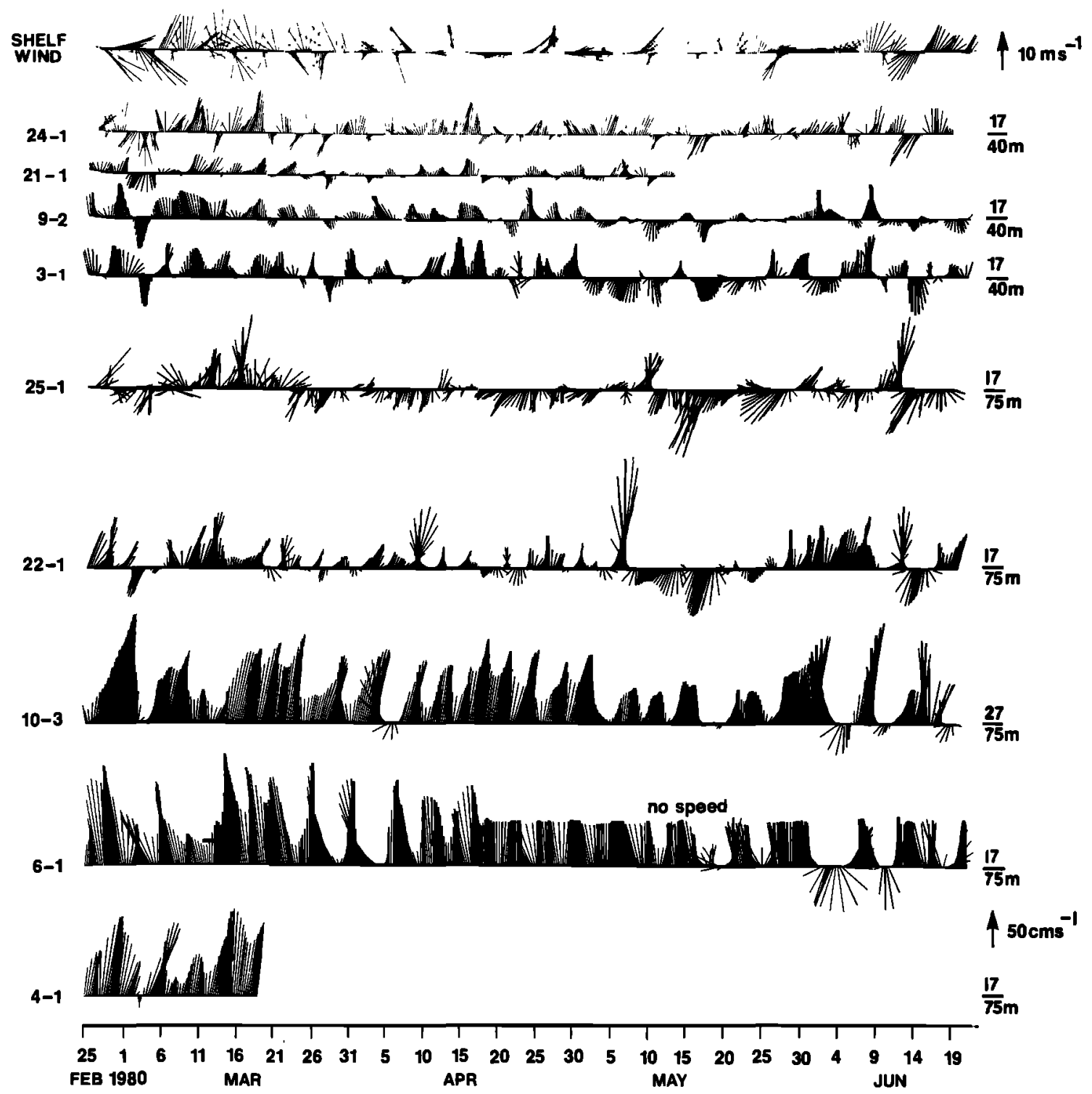

Fig. 2. Time series of 6-hour rotated 40-HLP wind and current vectors from the upper layer for February 25 to June 21, 1980. Current meter identification is given on the left; instrument and water depths on the right with scale arrows.

the shelf break moorings and 17 and $37 \mathrm{~m}$ on the moorings at the $40-\mathrm{m}$ isobath, with upper floatation at $15 \mathrm{~m}$. Vertical resolution was enhanced at the $30^{\circ} \mathrm{N}$ transect with six current meters at the 75-m isobath at depths of $7,17,27,45,60$, and $72 \mathrm{~m}$ (mooring 10) and four current meters at the $40-\mathrm{m}$ isobath at depths of 7, 17, 27, and $37 \mathrm{~m}$ (mooring 9). The upper current meter at mooring 10 was a General Oceanics winged device set to burst sample over surface wave periods. The top instrument on mooring 9 was an experimental Aanderaa modified at the University of Miami for use in shallow water by replacing the Savonius rotor with a Weller propeller. Its performance has been described by Leaman et al. [1982]. The current meters at the Cape Romain transect were all VACM's. Local shelf wind data were obtained from an NDBO buoy stationed between moorings 9 and 10. Additional wind and sea level data were obtained from coastal stations. Low-frequency (subtidal) time series of all data sets were obtained by filtering with a 40 -hour low-pass Lanczos filter kernel to remove variance associated with tidal and inertial motions. Semidiurnal tides are attenu- ated by more than $10^{5}$ by the filter, which results in a 4-day truncation at the start and end of the records. The filtered data were subsampled every 6 hours, and current and wind vectors were rotated to align with the local topography, such that the velocity components $(u, v)$ are positive in the offshore and northward along-shelf directions, respectively.

\section{Low-Frequency Current and Temperature Fluctuations}

\section{Time Domain}

Low-frequency wind and upper layer currents along the outer shelf are shown in Figure 2. The influence of the Gulf Stream is clearly indicated at the shelf break where current speeds were greater than $100 \mathrm{~cm} \mathrm{~s}^{-1}$. South of $30^{\circ} \mathrm{N}$, strong northward flows persisted for most of the measurement period and current fluctuations were visibly coherent between stations (moorings 4, 6, and 10). Only five flow reversals were observed at the St. Augustine transect (mooring 10) during the 4-month 


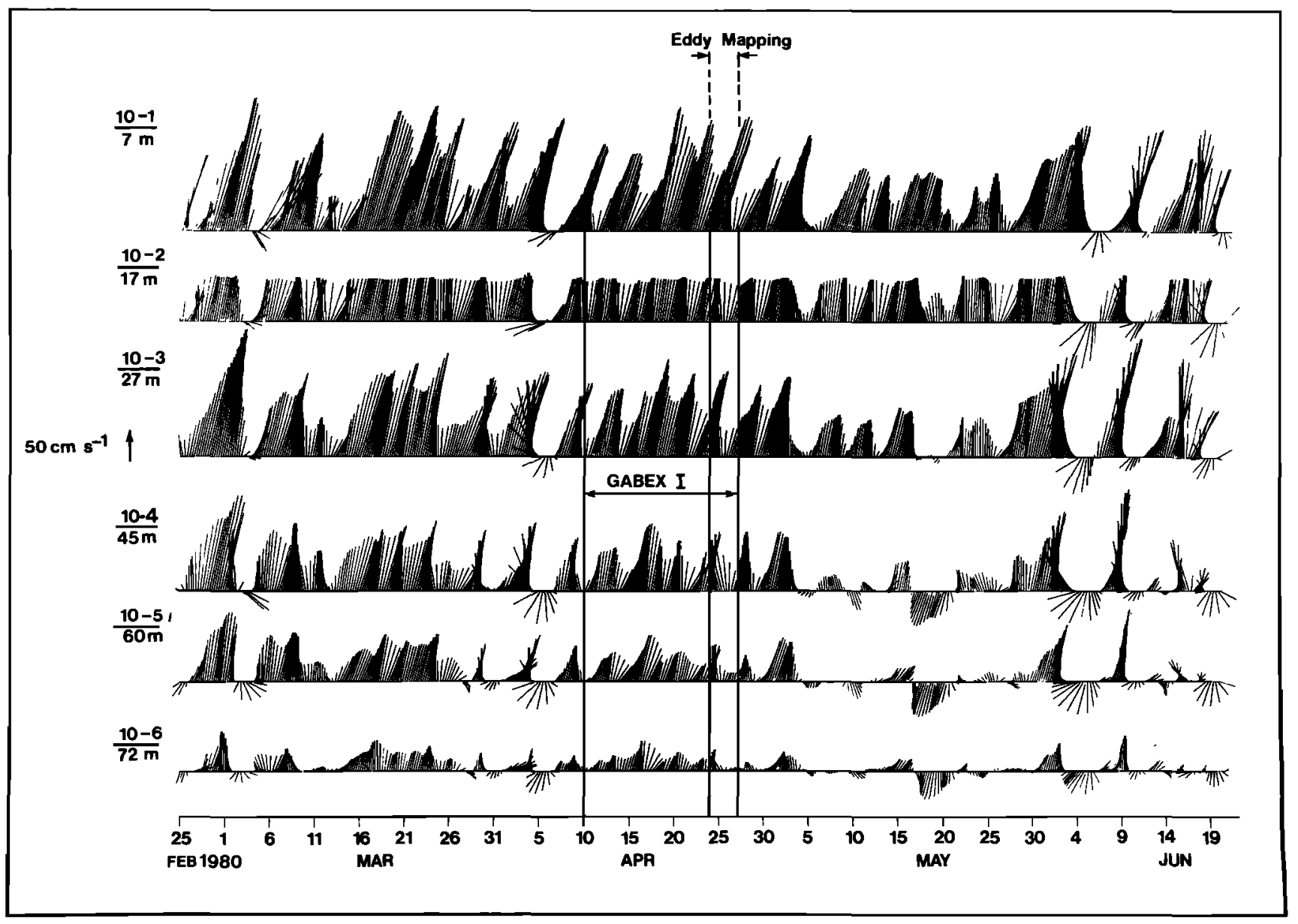

Fig. 3. Time series 6-hour rotated 40-HLP current vectors from mooring 10 (shelf break at $30^{\circ} \mathrm{N}$ ) of the GABEX 1 array. Mooring number, current meter identification, and instrument depth are shown to the left of each time series. Vertical lines indicate shipboard measurement periods.

study. The persistent northward flow was not observed at the shelf break off Savannah, Georgia (mooring 22), and the number of flow reversals increased. At the Cape Romain transect (moorings 24 and 25), prolonged southward flow events were observed at the shelf break that show little visual similarity to the currents off Savannah (mooring 22). Along the 40-m isobath, low-frequency currents in the upper layer at times show significant visual coherence between events at all mooring sites and shelf winds. Current amplitudes were also similar in magnitude between sites with little indication of any seasonal trend.

The vertical distribution of subtidal currents and temperature at the St. Augustine transect is shown in Figures 3-6. Current and temperature fluctuations were strongly coupled at the shelf break throughout the vertical array. Onshore flow events that occurred nearly simultaneously over the vertical array were followed closely by decreasing along-shelf currents and decreasing temperatures. Thus cold temperature anomalies occurred with cyclonic perturbations of the basic northward flow, and the effect was observed over the total water column. Over the total 4-month experiment, approximately 20 disturbances of this type were observed, giving an average period of about 6 days (Figures 5 and 6, events 1-14). Vertical shears at the shelf break ranged from about $2 \times 10^{-3} \mathrm{~s}^{-1}$ to $1 \times 10^{-2}$ $\mathrm{s}^{-1}$ in the fluctuations and $1 \times 10^{-2} \mathrm{~s}^{-1}$ in the mean, indicating a significant baroclinic component in both the fluctuating and mean parts of the flow. The baroclinicity was greatest at times of maximum northward currents, indicating periods when the Gulf Stream front was located near the shelf break.

Significant visual coherence is observed for wind stress events over the horizontal extent of the current meter array and between wind stress and current events at the 40-m isobath (Figure 4). Wind stress over the shelf at $30^{\circ} \mathrm{N}$ was approximately 3 to 4 times greater than wind stress at the coastal sites.

Current fluctuations at the $40-\mathrm{m}$ isobath were highly correlated over the vertical array as was temperature (Figures 3-6), but the correlation between currents and temperature does not appear to be as strong as at the shelf break. Current perturbations at the $40-\mathrm{m}$ isobath showed little change in amplitude with depth. The vertical shear of the mean flow was only $2 \times 10^{-4} \mathrm{~s}^{-1}$, indicating a strong barotropic character. Vertical shear in the fluctuations ranged from about 1 to $7 \times 10^{-3}$ $\mathrm{s}^{-1}$ with no significant difference between northward or southward flow events. The signature of the cold, cyclonic perturbations observed at the shelf break is not as clear at $40 \mathrm{~m}$ but is still recognizable for many of the events $(5,6,7,8,11,12,13$, and 14 of Figure 6).

Temperature fluctuations at the shell break ranged from $\pm 2^{\circ}$ to $\pm 8^{\circ} \mathrm{C}$ and were nearly in phase at all vertical positions. Temperature oscillations at $\mathbf{4 0} \mathrm{m}$ had smaller amplitudes and less vertical correlation than at the shelf break. On several occasions, temperature 'jumps' occurred as the water column 


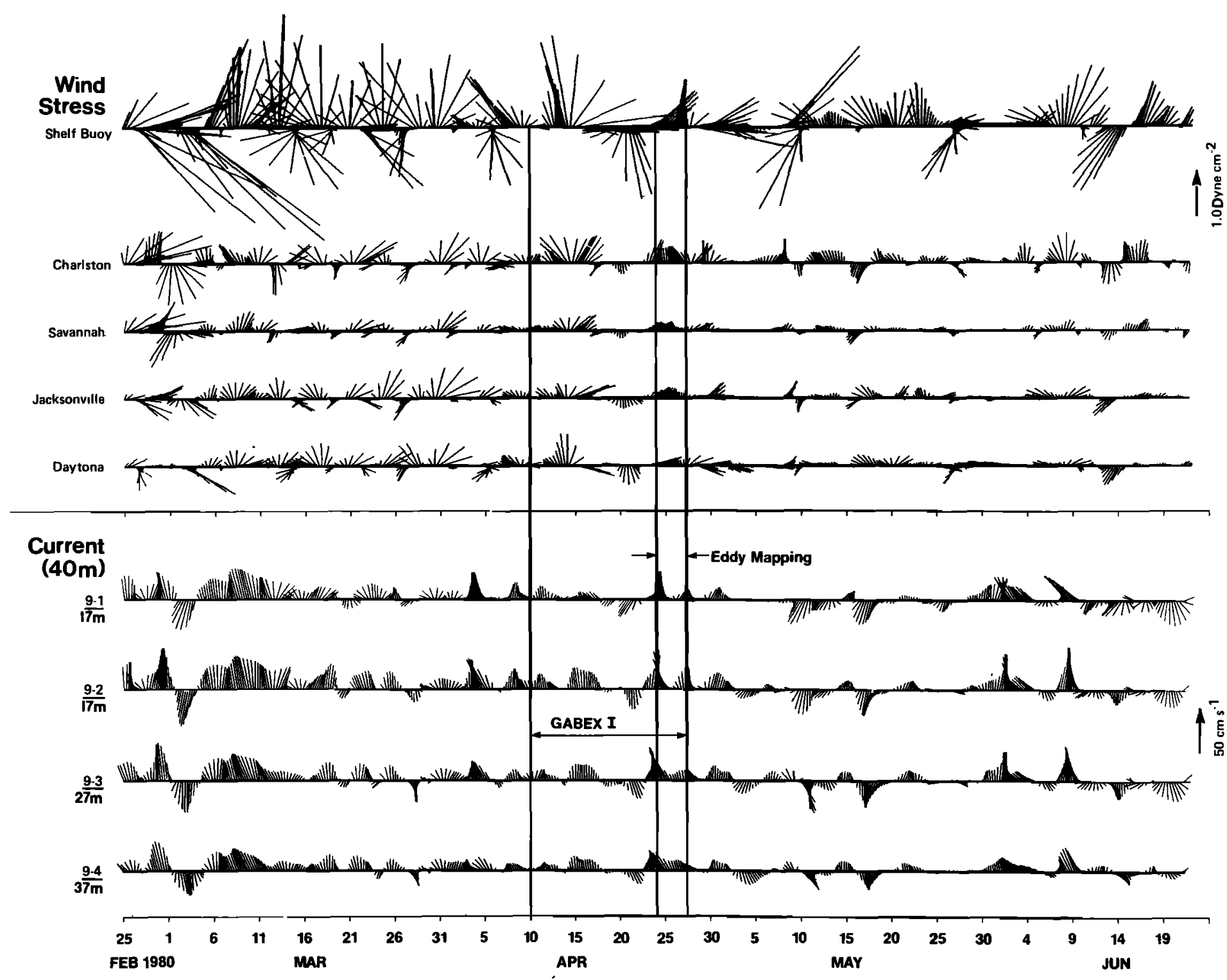

Fig. 4. Time series of 6-hour rotated 40-HLP buoy and coastal wind stress vectors and current vectors from mooring $9\left(40-\mathrm{m}\right.$ isobath at $\left.30^{\circ} \mathrm{N}\right)$ of GABEX 1 array. 


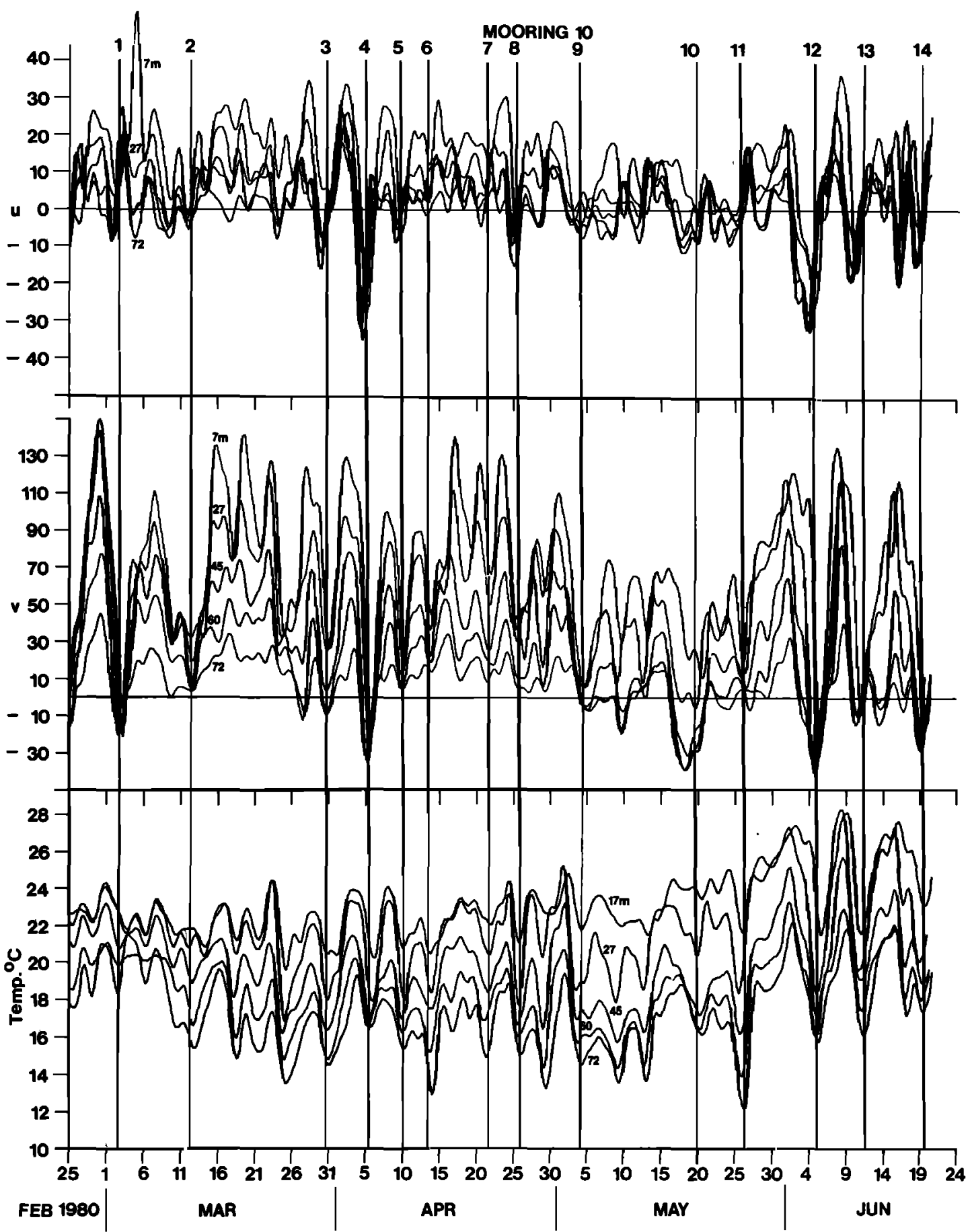

Fig. 5. Time series of 6-hour rotated 40-HLP $u, v$, and $T$ from mooring 10 . Vertical lines are for event identification.

suddenly warmed, which is indicative of advection of a warm front past the mooring. Northward current speeds also increased at these times.

A seasonal increase in stratification is apparent at both mooring locations but is more pronounced at $40 \mathrm{~m}$. Stratification generally extended to within $3 \mathrm{~m}$ of the bottom at the shelf break except during periods of sharp temperature declines when near-isothermal conditions occurred in the lower 15 to 30 $\mathrm{m}$. Stratification was normally higher for increasing temperatures than for decreasing temperatures, probably reflecting the proximity of the Gulf Stream front. At the $40-\mathrm{m}$ isobath an isothermal bottom layer of at least 13-m thickness existed for most of the experiment.
Low-frequency current and temperature records indicate that the largest amplitude fluctuations occurred in a 2-day to 2-week period band. Therefore the data were band-pass filtered about this band by smoothing the low-frequency time series with a 2-week high-frequency cutoff, which removes fluctuations with periods of less than $\mathbf{4 0}$ hours and greater than 2 weeks. The band-pass cross-shelf $(u)$, along-shelf $(v)$, and temperature $(T)$ time series from the upper and lower layers were compared to the band-pass shelf wind components and coastal sea level measured at the mouth of the Savannah River for the period from May 15 to June 17, 1980 (Figures 7 and 8).

Cold, cyclonic perturbations are observed to propagate northward along the shelf break at about $55 \mathrm{~cm} \mathrm{~s}^{-1}$. Legeckis 


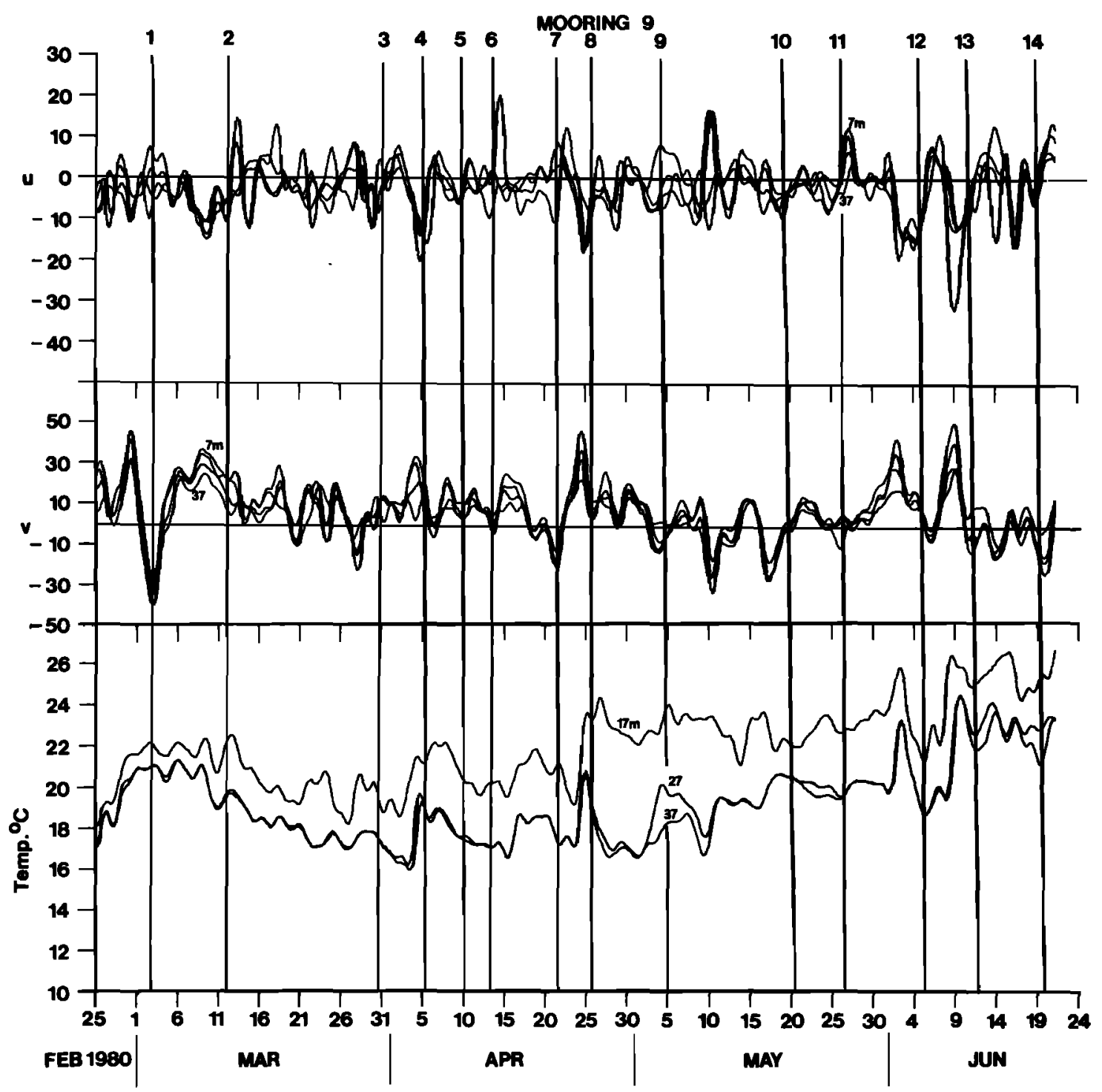

Fig. 6. Time series of 6-hour rotated 40-HLP $u, v$, and $T$ from mooring 9. Vertical lines are for event identification.

[1979] observed a $46 \mathrm{~cm} \mathrm{~s}^{-1}$ mean northward propagation speed of meanders downstream of the Charleston Bump. The propagation is clearest in the lower layer owing to the greater number of available instruments but is also readily apparent in the upper layer. Events 10-14 traveled to the north at nearly a constant speed. Event 12 was clearly recognizable over alongshelf distances of up to $425 \mathrm{~km}$. The signature of these perturbations appears more pronounced at the Cape Romain transect, especially the cross-shelf component which was larger in magnitude than the along-shelf component in the upper layer at mooring 25. This location is downstream of the Charleston Bump in a region of observed meander amplification [Bane, this issue]. Cold, cyclonic perturbations were observed to propagate northward along the shelf break at speeds of $50-70 \mathrm{~cm}$ $\mathrm{s}^{-1}$ throughout the 4-month study (Figure 5, events 1-14) and were not visually correlated with either wind or coastal sea level events.

Propagating disturbances were more difficult to identify at the $40-\mathrm{m}$ isobath. At the $27-$ and $37-\mathrm{m}$ levels, $u$ and $v$ appear to be $180^{\circ}$ out of phase (rectilinear) for a large part of the records and not significantly related to temperature fluctuations. At the 7 - and $17-\mathrm{m}$ levels, $u$ and $v$ were only occasionally out of phase and the correlation with temperature is not clear. Nonpropagating events were many times observed at the $40-\mathrm{m}$ isobath when northward (southward) current fluctuations occurred simultaneously over the along-shelf extent of the array following northward (southward) winds and coastal sea level setdown (setup) (Figures 7 and 8, events a-d). Nonpropagating events of this type are occasionally observed at the shelf break (event a). Mixed responses also appear to occur when propagating and stationary events interact and large-amplitude current fluctuations may occur when these events are in phase (events $c$ and $\mathrm{d}$ at mooring 25). Nonpropagating fluctuations were a major part of the current variability at the $40-\mathrm{m}$ isobath and a strong correlation with wind events is evident, especially in the lower layer (Figures 2, 4, 7, and 8). However, propagating disturbances were sometimes observed at $40 \mathrm{~m}$ and were visibly coherent with events at the shelf break (events $11,12,13$, and 14).

\section{Frequency Domain}

Cross spectra of cross-shelf and along-shelf low-frequency velocity components from shelf break and 40-m isobaths and 


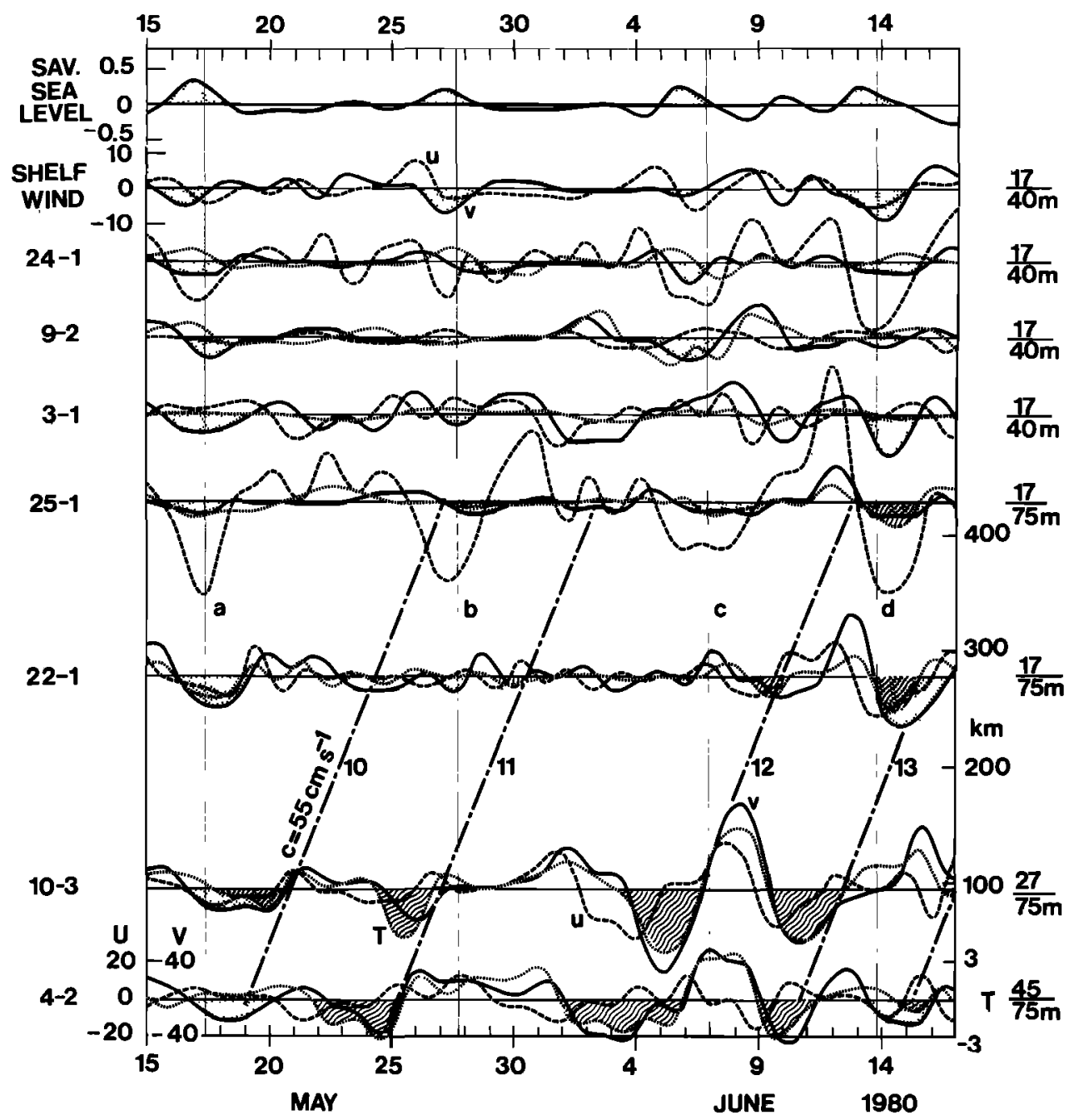

Fig. 7. Time series of 6-hour rotated band-pass-filtered upper layer current components ( $\mathrm{cm} \mathrm{s}^{-1}$ ) $u$ (dashed lines), $v$ (solid lines), and $T$ (dotted lines); shelf wind components $\left(\mathrm{m} \mathrm{s}^{-1}\right) u$ (dashed lines), $v$ (solid lines) for the period May 15 to June 17. Propagating events $(10-13)$ shown by slanted lines with phase speed $c=55 \mathrm{~cm} \mathrm{~s}^{-1}$ connecting cold anomalies at the shelf break (wavy shading). Nonpropagating events ( $a-d)$ shown by vertical lines connecting southward wind and current events (dotted shading) and coastal sea level setup (dotted shading).

shelf winds are presented in Figures 9 and 10. Spectra from records taken at the 27-m level at the shelf break off St. Augustine are shown, for they are typical of the total water column at this location. Low-frequency currents at the shelf break show well-defined energy peaks at periods of 5 to 6 days for $u$ and 7 to 9 days for $v$. The velocity components were coherent at these periods with $u$ leading $v$ by about $50^{\circ}$ to $70^{\circ}$, which is indicative of propagating cyclonic fluctuations. Coherence was also significant at periods of $3,2.5$, and 2 days but the energy levels were considerably reduced. Spectra of currents from the 40-m isobath also show energy peaks at 5- to 6-day periods for $u$ and 7- to 9-day periods for $v$, but they are not as well resolved as at the shelf break and the coherence is weak. The only significant coherence between $u$ and $v$ in the upper layer $(7 \mathrm{~m})$ was at 2and 4-day periods. In the lower layer the velocity components were $180^{\circ}$ out of phase for periods greater than 2 days. Coherence was high for periods greater than 9 days but only marginally significant at periods of $1.8,2.5$, and 3.3 to 4 days. Shelf winds had energetic coherent fluctuations at the same periods as the coherent lower layer motions at the $40-\mathrm{m}$ isobath (1.8, $2.5,3$ to 4 , and 12 days). Neither the currents at $40 \mathrm{~m}$ nor the winds showed significant coherence between $u$ and $v$ in the 5- to 9-day period band where the coherence was highest at the shelf break.

Coherence and phase relationships between along-shelf currents and along-shelf winds are shown in Figure 11; along-shelf currents versus coastal sea level are shown in Figure 12. Currents at the shelf break were marginally correlated with wind and sea level at the 9-day period. This correlation was only apparent in the lower layer. Along-shelf flow in the upper layer at the 40-m isobath showed significant coherence with alongshelf winds at periods of 4 and 7 to 12 days and high coherence with sea level at periods of 7 to 12 days. Currents were strongly correlated with wind and sea level in the lower layer at the period bands of 3 to 4 and 9 to 12 days. The coherence was generally higher between currents and sea level at these periods. Subtidal time series indicate that lower-layer velocity fluctuations lag the wind by about 12 to 16 hours and sea level by about 6 to 12 hours. Also sea level was highly coherent with along-shelf winds at 10-day periods and with cross-shelf winds at 2- to 7-day periods and appeared to lag wind events by about 6 hours. 


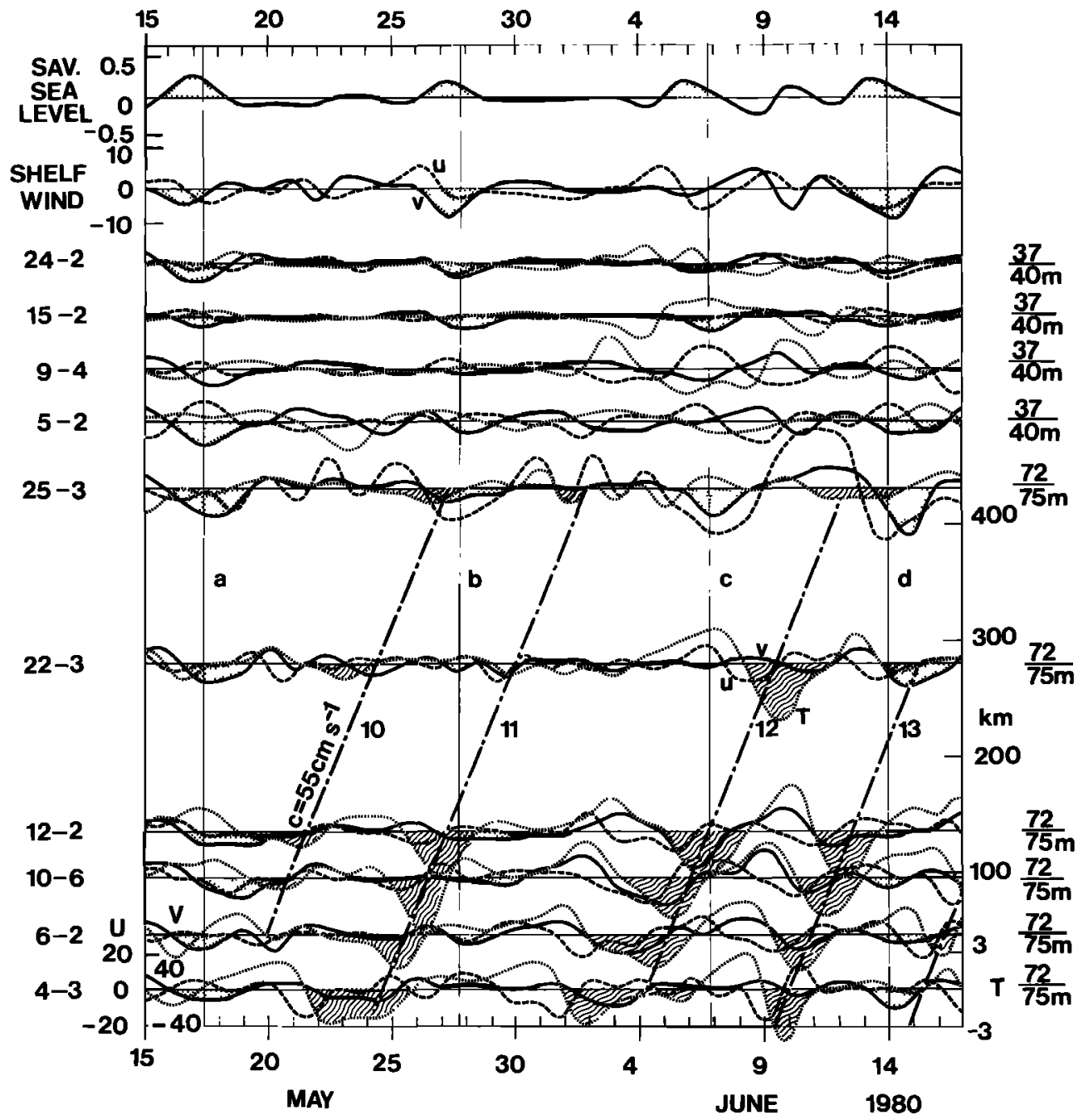

Fig. 8. Time series of 6-hour rotated band-pass-filtered lower layer current components ( $\mathrm{cm} \mathrm{s}^{-1}$ ) $u$ (dashed lines), $v$ (solid lines), and $T$ (dotted lines); shelf wind components $\left(\mathrm{m} \mathrm{s}^{-1}\right) u$ (dashed lines), $v$ (solid lines) for the period May 15 to June 17. Propagating events (10-13) shown by slanted lines with phase speed $c=55 \mathrm{~cm} \mathrm{~s}^{-1}$ connecting cold anomalies at the shelf break (wavy shading). Nonpropagating events ( $\mathrm{a}-\mathrm{d}$ ) shown by vertical lines connecting southward wind and current events (dotted shading) and coastal sea level setup (dotted shading).

Coherence and phase of the velocity and temperature fluctuations in the 7- to 9-day period band are plotted against alongshelf separation distance from combinations of current meter pairs in Figures 13-16. The kinetic energy density in the upper and lower layer at each mooring site is also shown. Coherence falls off rapidly at the shelf break and defines an along-shelf coherent length scale of approximately $100 \mathrm{~km}$ for $u, v$, and $T$ in the energetic 7- to 9-day period band. Phase estimates show a near-linear increase of negative phase with separation for distances less than the coherent length scale. Negative phase lags indicate northward propagation, and the scatter of points tends to fall around a line equivalent to a constant phase speed of 55 $\mathrm{cm} \mathrm{s}^{-1}$. The kinetic energy of along-shelf fluctuations in the 7to 9-day period band was highest in the upper layer in the southern portion of the array and decreased northward. Minimum fluctuation energy occurred off Savannah (mooring 22). No significant differences occurred between mooring sites for the along-shelf flow in the lower layer or the cross-shelf flow for upper and lower layers. The amplitudes of temperature fluctuations were larger over the southern portion of the array, without any significant differences between upper and lower layers.

At the 40-m isobath, coherence of along-shelf current fluctuations in the 7- to 9-day band was high over along-shelf distances of up to $425 \mathrm{~km}$ with small and nearly constant phase lags, which is indicative of nonpropagating fluctuations (Figure 16). The cross-shelf velocity components and temperature did not show any consistent along-shelf coherent features, so they are not presented. Also, along-shelf coherence and phase estimates computed for fluctuations in the 5- to 6-day period band were similar to those shown for the 7- to 9-day band at both the 75- and 40-m isobaths, and so they are not presented.

Cross-shelf estimates of coherence and phase between instrument pairs on the $75-$ and $40-\mathrm{m}$ isobaths at $30^{\circ} \mathrm{N}$ (moorings 9 and 10) showed significant coherence for velocity components in the 5- to 9-day period band. The highest coherence for $u$ was centered at the 5-day period with fluctuations at $\mathbf{4 0} \mathrm{m}$ leading slightly in phase. The peak coherence for $v$ was centered at the 7-day period with a near-zero phase. Temperature was only coherent in the lower half at periods of about 4 and 7 to 12 days 

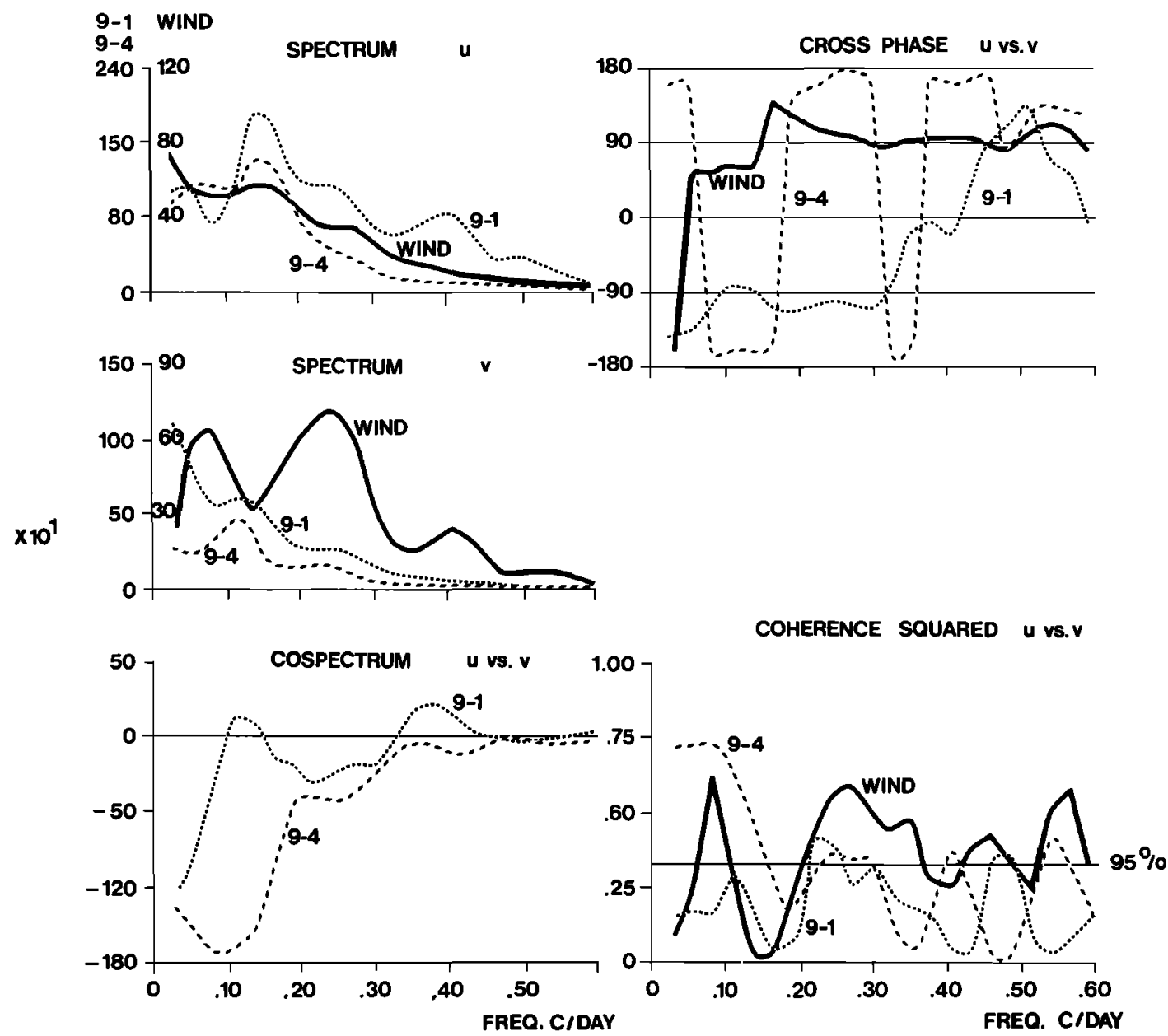

Fig. 9. Spectra $\left(\mathrm{cm}^{2} \mathrm{~s}^{-2} \mathrm{CPD}^{-1}\right)$, cospectrum, cross phase, and coherence squared between $u$ and $v$ 40-HLP rotated velocity components of buoy winds, 9-1 and 9-4 currents for GABEX 1. Degrees of freedom, 16.8; number of lags, 74; effective bandwidth, $0.036 \mathrm{CPD}$. Spectra scale on left is for currents and on right is for wind.

with fluctuations at the offshore mooring leading by about $90^{\circ}$ in phase.

\section{Mean Conditions}

Mean flows over the outer shelf appear to be closely related to the position of the Gulf Stream (Figure 17). South of the Savannah transect the western edge of the Gulf Stream lies close to the shelf break and northward mean currents of about $60 \mathrm{~cm} \mathrm{~s}^{-1}$ result in the upper layer. Onshore/offshore displacements of the Gulf Stream front are generally less than $15 \mathrm{~km}$ in this region [Bane and Brooks, 1979]. At the southern transect there was a mean onshore flow near the bottom at the shelf break and offshore flow at the four moorings sites to the north, indicating the possibility of a net water movement onto the shelf south of the array. Mean flows were generally weak at the Savannah transect for the 4-month and 2-week means. Seaward of the Savannah transect a topographic anomaly know as the 'Charleston Bump' [Bane and Brooks, 1979] protrudes onto the Blake Plateau and into the path of the Gulf Stream, apparently forcing a quasi-permanent offshore meander of the stream on the lee side of the 'Bump' (see, for example, Brooks and Bane [1978], Pietrafesa et al. [1978], and Legeckis [1979]). The 4-month averages at the northernmost ransect off Cape Romain indicate a significant southward mean flow in the lower layer at the shelf break. Downstream of the bump, en- larged east-west meanders can displace the Gulf Stream front up to $100 \mathrm{~km}$ from the shelf break [Legeckis, 1979; Bane and Brooks, 1979]. Thus off Cape Romain the Gulf Stream front is normally located a considerable distance offshore of the moorings, and the observed mean southward flow must in some way be connected to this displacement, possibly due to the cumulative effect of the occurrence of filament-shaped frontal disturbances that are known to enlarge and produce southward flow events downstream of the bump [Legeckis, 1979; Bane et al., 1981; Brooks and Bane, 1981] or as a response to the cold dome' formed in the lee of the bump [Singer et al., this issue; Bane, this issue]. The Savannah area appears to be a transition region between the strong mean northerly and southerly flow regimes.

Analysis of cumulative weekly means indicates that it normally took from 10 to 15 weeks for mean velocity components to stablize (remain constant with $\pm 10 \%$ of the total record mean). Mean temperature became stable in about 5 to 10 weeks. There was no obvious spatial dependency in the stability estimates, indicating that the means began to stabilize after a sufficient number of events occurred to average out individual event differences. Total record lengths were 16.5 weeks, except for current meters 21-1, 21-2, and 22-3 with lengths of about 11 weeks. Without longer record lengths it is impossible to know if the means would remain stable over longer periods. Most likely 

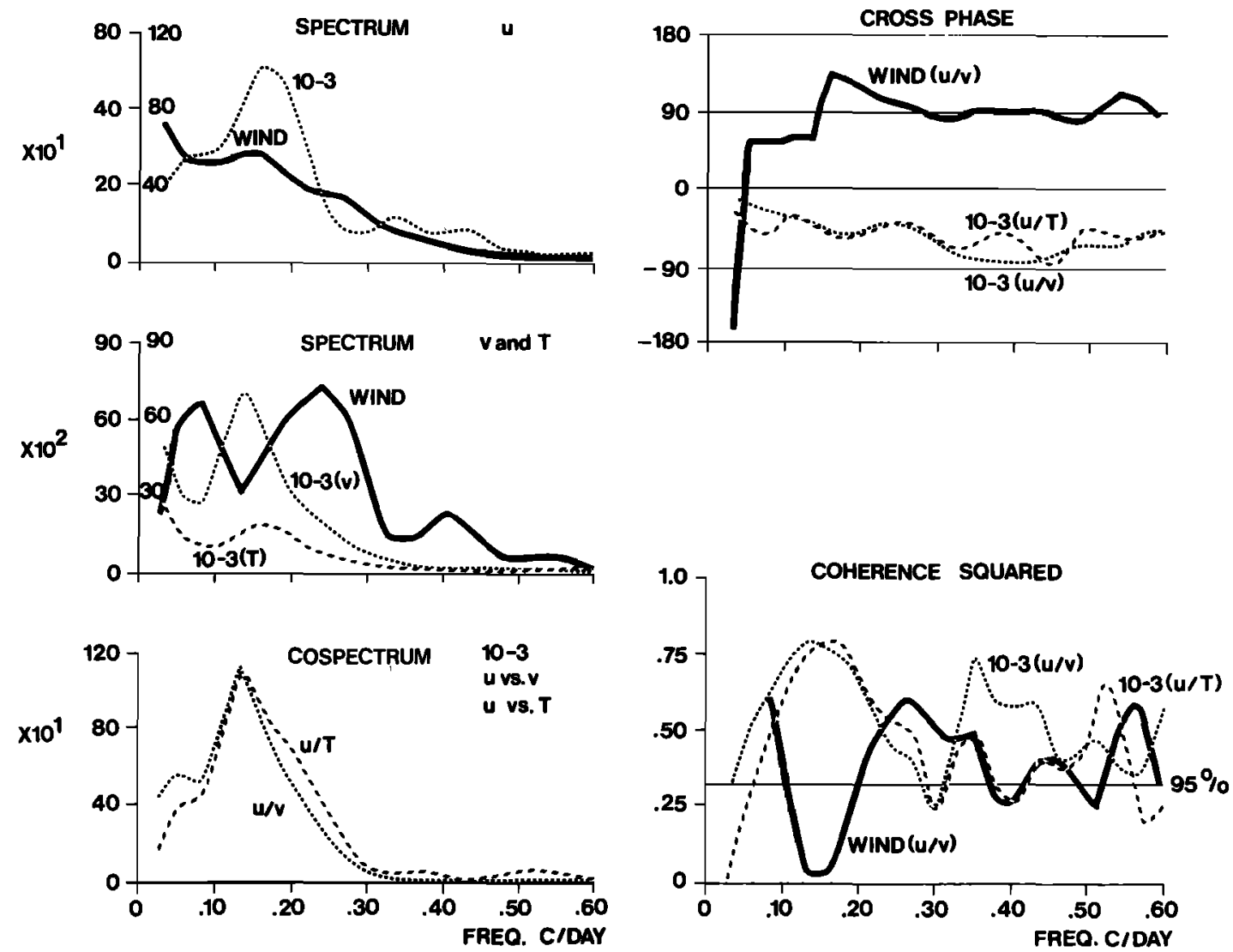

Fig. 10. Spectra $\left(\mathrm{cm}^{2} \mathrm{~s}^{-2} \mathrm{CPD}^{-1}\right)$, cospectrum, cross phase, and coherence squared between $u$ and $v$ 40-HLP rotated velocity components of buoy winds, 10-3 currents and temperature $(T)$ for GABEX 1 . Degrees of freedom, 16.8; number of lags, 74; effective bandwidth, 0.036 CPD. Spectra scale on left is for currents and on right is for wind.

there will be seasonal effects on the shelf that may influence the 40-m isobath means. Seasonal changes at the shelf break were found to be small in comparison with Gulf Stream influences on the 2-day to 2-week time scale [Lee et al., 1981], so the shelf break means may be more representative of annual or longer averages, at least for the region south of Savannah.

\section{Discussion}

\section{Wind Response}

Low-frequency along-shelf current fluctuations at the $40-\mathrm{m}$ isobath were highly coherent with the along-shelf wind and coastal sea level at periods of 3 to 4 and 10 to 12 days. The current fluctuations were nearly equal in magnitude and close in phase over the $425-\mathrm{km}$, along-shelf array spacing and $40-\mathrm{m}$ water depth, indicating a nonpropagating barotropic response to wind-driven sea level fluctuations. Coastal sea level elevations were highly responsive to both along-shelf and crossshelf winds. Assuming wind-driven sea level variations are small at the shelf break compared to the coast, then a setup (setdown) of sea level ( $n$ ) at the coast will generate a cross-shelf surface slope that is in approximate geostrophic balance with the Coriolis force resulting in a southward (northward) barotropic flow $v_{g}=(g / f)(\partial n / \partial x)$.

The magnitude of the current response for observed coastal sea level amplitudes of $20-30 \mathrm{~cm}$ ranges from approximately 20 to $45 \mathrm{~cm} \mathrm{~s}^{-1}$ for shelf widths of the array and assuming a linear slope to a constant mean sea level at the shelf break. The amplitudes of low-frequency currents at the $40-\mathrm{m}$ isobath appear to fall within this range.

A similar frictional equilibrium response was observed in the Mid-Atlantic Bight [Beardsley and Butman, 1974; Scott and Csanady, 1976] and on the west coast [Hickey and Hamilton, 1980] and appears to be a fundamental part of the dynamics of coastal wind-driven flow. Southward propagating continental shelf waves were not observed in the coastal sea level data or current meter data. Propagating disturbances are observed to travel north in this region owing to advection by the Gulf Stream and are restricted to the outer shelf.

\section{Gulf Stream Frontal Eddies}

Hydrographic and biological observations of shelf waters in the region of the current meter array and the adjacent Gulf Stream front were made during April 10 to 26. Two ships were involved: Eastward and Columbus Iselin. The Eastward was used to investigate shelf processes, while the Columbus Iselin was used to locate and track Gulf Stream frontal disturbances with the aid of a telefax system for receiving satellite sea surface temperature (SST) images from the NOAA-NESS field station in Miami. The Iselin also received a detailed SST map every 3 days from a U.S. Coast Guard aircraft equipped with an airborne radiation thermometer. Current and temperature records from the outer shelf indicate that a succession of four cold cyclonic perturbations of the strong northward mean flow occurred during the shipboard sampling period (Figures 3-6: events $5,6,7$, and 8 ). These events were advected northward at 
Shelf Wind vs. Current
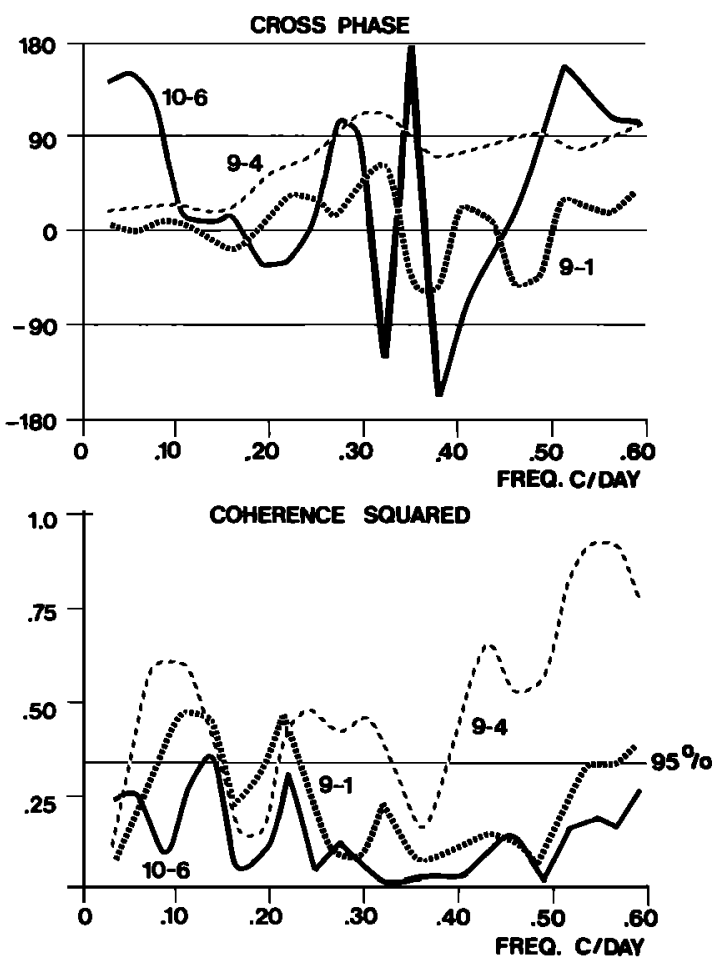

Fig. 11. Cross phase and coherence squared between 40-HLP rotated buoy winds ( $v$ component) and currents ( $v$ component) from 9-1, 9-4, and 10-6. Degrees of freedom, 16.8; number of lags, 74; effective band width, 0.036 CPD.

a mean speed of about $60 \mathrm{~cm} \mathrm{~s}^{-1}$ which is close to the mean northward speed observed at the shelf break and also close to the northward propagation speed determined for $u, v, T$ fluctuations in the 5- to 9-day period band (Figures 13-15). The onset of each disturbance produced onshore flow followed by decreasing temperature and northward current speeds throughout the water column at the shelf break. The end of the events produced offshore flow coupled with increasing temperature and northward speeds. A similar but less pronounced response occurred at the $40-\mathrm{m}$ isobath. Shipboard observations indicate that the cold anomalous waters consisted of newly upwelled nutrient enriched North Atlantic Central Water [Dunstan and Atkinson, 1976; Yoder et al., 1981].

The formation, growth, and northward movement of event 8 was observed with shipboard hydrography and remote thermal imagery from April 21 to 27. It was first observed with shipboard SST mapping as a small disturbance of the Gulf Stream surface thermal front off Cape Canaveral on April 21, (T. N. Lee, unpublished report, 1981). On April 22 and 23 it was clearly observable in satellite thermal imagery as a well-defined frontal 'shingle' [Von Arx et al., 1955] seaward of Cape Canaveral (Figures 18 and 19). The shingle thermal pattern has been found to be the characteristic SST signature of cyclonic cold core frontal eddies in this region [Lee et al., 1981]. Detailed hydrographic sampling was obtained through the disturbance during a 20-hour period on April 24 and 25 and again over a 37-hour period on April 25 and 26 (Figures 20 and 21). It took the combined effort of two ships to resolve the thermal field of this rapidly moving event.

The northward speed of the event was estimated using remote imagery, shipboard mapping and current meter records, all of which indicated a speed of about $55 \mathrm{~cm} \mathrm{~s}^{-1}$. A warm filament of $23^{\circ}$ to $24^{\circ} \mathrm{C}$ Gulf Stream water approximately 15 to $20 \mathrm{~m}$ in depth extended southward from the front around a cold core with a minimum surface temperature of $22^{\circ} \mathrm{C}$. The alongshelf dimension of the feature was approximately $130 \mathrm{~km}$, and the cross-shelf distance from western edge of the filament to the center of the cold core was about $25 \mathrm{~km}$. A typical temperature, density, and nitrate section through the center of the feature is shown in Figure 22. Uplifted temperatures in the cold dome extended across the outer shelf beneath the warm filament in a cold subsurface intrusion of nutrient enriched waters. Euphotic zone nitrate concentrations of $5 \mu \mathrm{mol} \mathrm{l}^{-1}$ were observed beneath the warm filament and $10 \mu \mathrm{mol} 1^{-1}$ near the shelf break

SST and hydrographic section data (Figures 20-22) indicate that the cold core of event 8 passed directly through mooring 10 and the western edge of the warm filament passed through mooring 9. The low-frequency temperature records from mooring sites 9 and 10 further substantiate this movement (Figures 5 and 6). At mooring 10, temperature decreased then increased at all vertical positions between April 24 and 27, which was the time the cold core passed the mooring. Temperature from mooring site 9 first increased from April 24 to 25 at all levels then decreased in the lower $13 \mathrm{~m}$ and remained high in the upper $17 \mathrm{~m}$. The initial temperature increase appears related to the passage of the warm filament, which caused the temperature to remain high in the upper $17 \mathrm{~m}$ for the duration of the event. Below the level of the warm filament, temperatures decreased as the cold subsurface intrusion passed through the mooring.

The uplifted density structure in the cold core of the disturb-
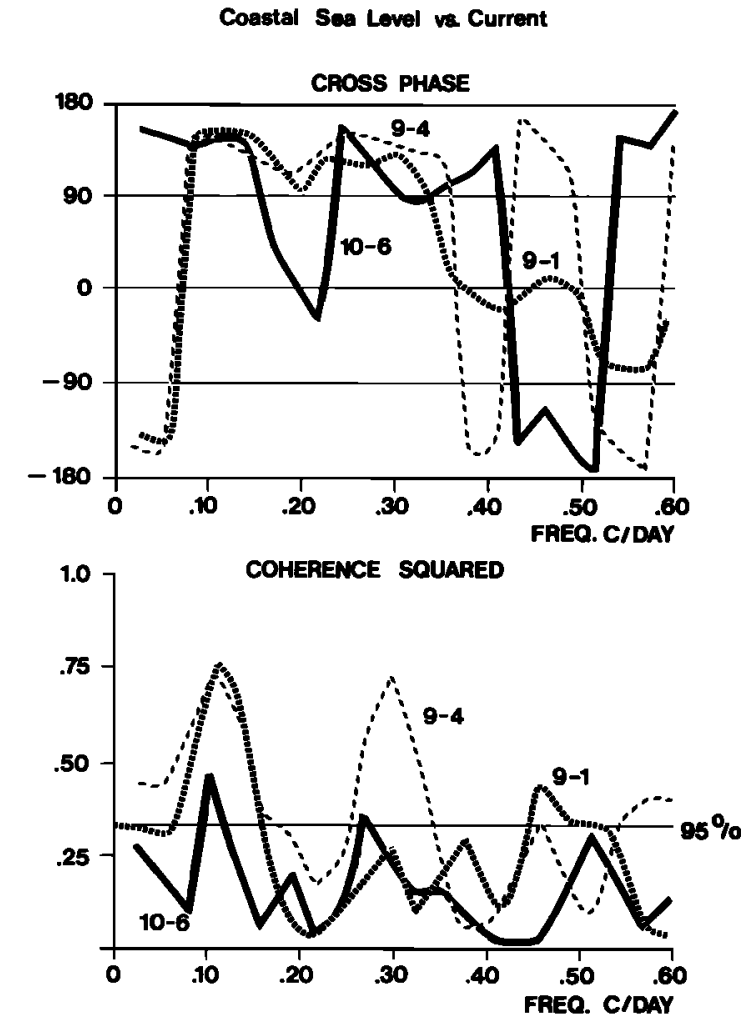

Fig. 12. Cross phase and coherence squared between 40-HLP Savannah sea level and currents ( $v$ component) from 9-1, 9-4, and 10-6. Degrees of freedom, 16.8; number of lags, 74 ; effective bandwidth, 0.036 CPD. 

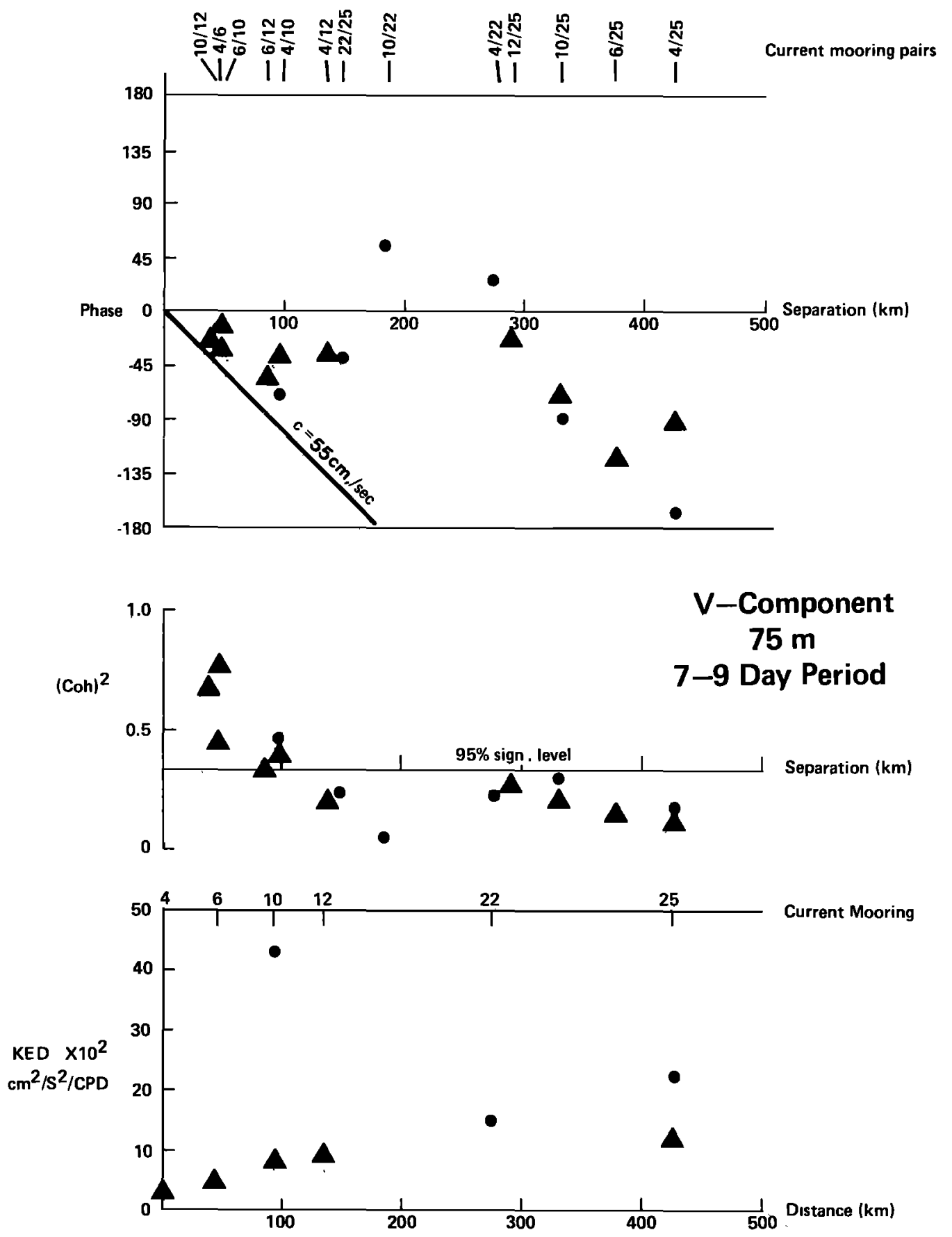

Fig. 13. Along-shelf coherence squared, phase, and energy density for the 40-HLP rotated $v$ component from current meter pairs at shelf break in 7- to 9-day period band; dots are for upper layer, and triangles are for lower layer.

ance indicates a cyclonic circulation with southward flow west of the core and northward flow on east. Previous investigations of Gulf Stream frontal eddies of the Georgia shelf [Lee et al., 1981] and in the Florida Straits [Lee, 1975; Lee and Mayer, 1977] have observed cyclonic current reversals in current meter records as shingles with similar properties as found in event 8 were encountered. However, low-frequency current records from mooring 9 and 10 during April show a persistent northward flow that is perturbed by a succession of cyclonic cold anomalies, but no flow reversals (Figures 3, 4, and 5). A fixed current meter records the mean flow $(\vec{v})$ plus eddy motions $(v)$ written as $v=\bar{v}+v^{\prime}$ for the along-shelf component. If the mean flow is larger than the eddy motion, a current reversal will not be observed at a fixed station. Band-pass filtering the data from 40 hours to 2 weeks removes the effect of the mean and shows cold cyclonic perturbations propagating northward along the shelf break at about $55 \mathrm{~cm} \mathrm{~s}^{-1}$, which was nearly the same speed as the mean (Figures 7 and 8). When the effect of the mean flow is removed, cyclonic flow reversals are observed at all levels at sites 9 and 10 during the passage of event 8 (Figure 23).

Southward flows within event 8 appear to be in approximate 

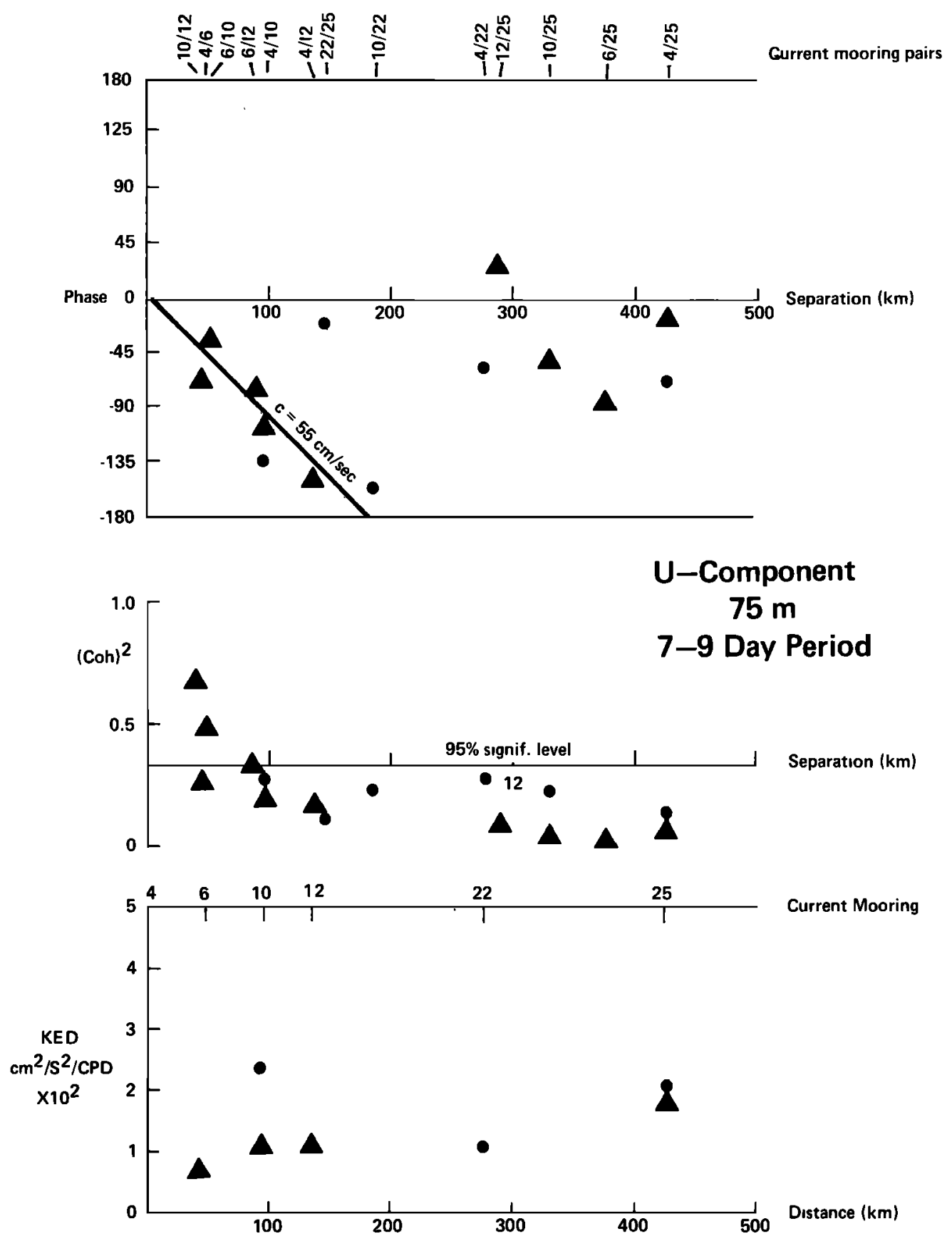

Fig. 14. Along-shelf coherence squared, phase, and energy density for the 40-HLP rotated $u$ component from current meter pairs at shelf break in 7- to 9-day period band; dots are for upper layer, and triangles are for lower layer.

geostrophic balance with the uplifted density structure in the cold core as determined from the thermal wind equation:

$$
\frac{\partial v}{\partial z}=\frac{g}{\rho f} \frac{\partial \rho}{\partial x}
$$

The daily averaged vertical shear measured at mooring 9 during the passage of event 8 (April 26) was about $5 \times 10^{-3} \mathrm{~s}^{-1}$ beneath the warm filament. The horizontal density gradient, right-hand side of (1), was about $4 \times 10^{-3} \mathrm{~s}^{-1}$ at the $17-\mathrm{m}$ level and $3 \times 10^{-3} \mathrm{~s}^{-1}$ at $37 \mathrm{~m}$ (from stations 337 and 339 of Iselin section 24). Anticyclonic circulation was not observed in currents within the filament ( $7-\mathrm{m}$ level), presumably due to the stronger cyclonic circulation within the larger cold anomaly. However, station spacing was not sufficient to resolve the relative density field of the warm filament. Thus the propagating cold cyclonic perturbations described here appear to be the same type of frontal eddies as found previously [Lee et al., 1981]. The only observable difference is that the northward propagation velocities were larger than eddy velocities for most of the events.

\section{Upwelling Velocity in Frontal Eddies}

Upwelling velocities $(w)$ in event 8 can be estimated by comparing vertical positions of isotherms in the cold core while 

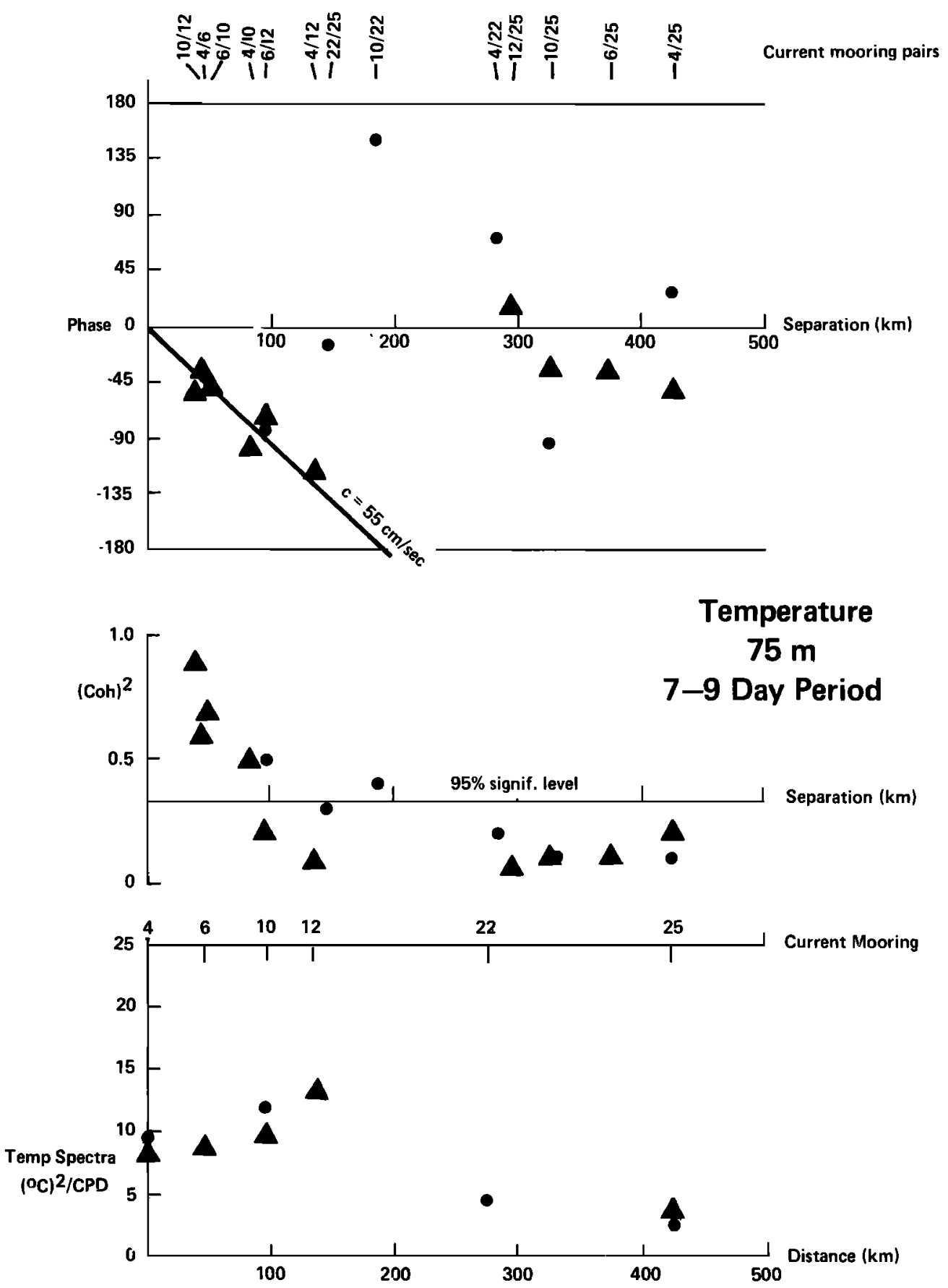

Fig. 15. Along-shelf coherence squared, phase, and energy density for the 40-HLP temperature from current meter pairs at shelf break in 7- to 9-day period band; dots are for upper layer, and triangles are for lower layer.

tracking the feature. The $17^{\circ} \mathrm{C}$ isotherm was uplifted $13 \mathrm{~m}$ in the core in a 37.8-hour period between Eastward station 366 (Eastward section 16, Figure 20) and Iselin station 339 (Iselin section 23 , Figure 21 ), which gives a vertical velocity of $10^{-2} \mathrm{~cm}$ $\mathrm{s}^{-1}$. Since subsurface temperature measurements can be aliased by internal tides, it becomes useful to also estimate $w$ from the conservation of relative vorticity $(\zeta)$ along a streamline. Following Arthur [1965] the conservation of relative vorticity in natural coordinates is

$$
f \frac{d w}{d z}=\frac{d \zeta}{d t}+\beta V
$$

where $\zeta=(V / R)-(d V / d n)$ and $\beta$ is the change in planetary vorticity $(f)$ with latitude; $\beta=1.35 \times 10^{-13} \mathrm{~cm}^{-1} \mathrm{~s}^{-1}$. Assuming a uniform flow $V$ which tends to follow the temperature pattern shown in Figure 20 with cyclonic curvature of radius $R$ around the cold core (the shear vorticity $d V / d n$ in the filament is assumed zero), then the vertical velocity at depth $h$ is given by

$$
w_{h}=-\frac{h}{f} \frac{d \zeta}{d t}-\frac{h \beta V}{f}
$$

The tangential velocity $V$ is assumed equal to the eddy velocity of event 8 or approximately $40 \mathrm{~cm} \mathrm{~s}^{-1}$ (Figure 23) and has a 

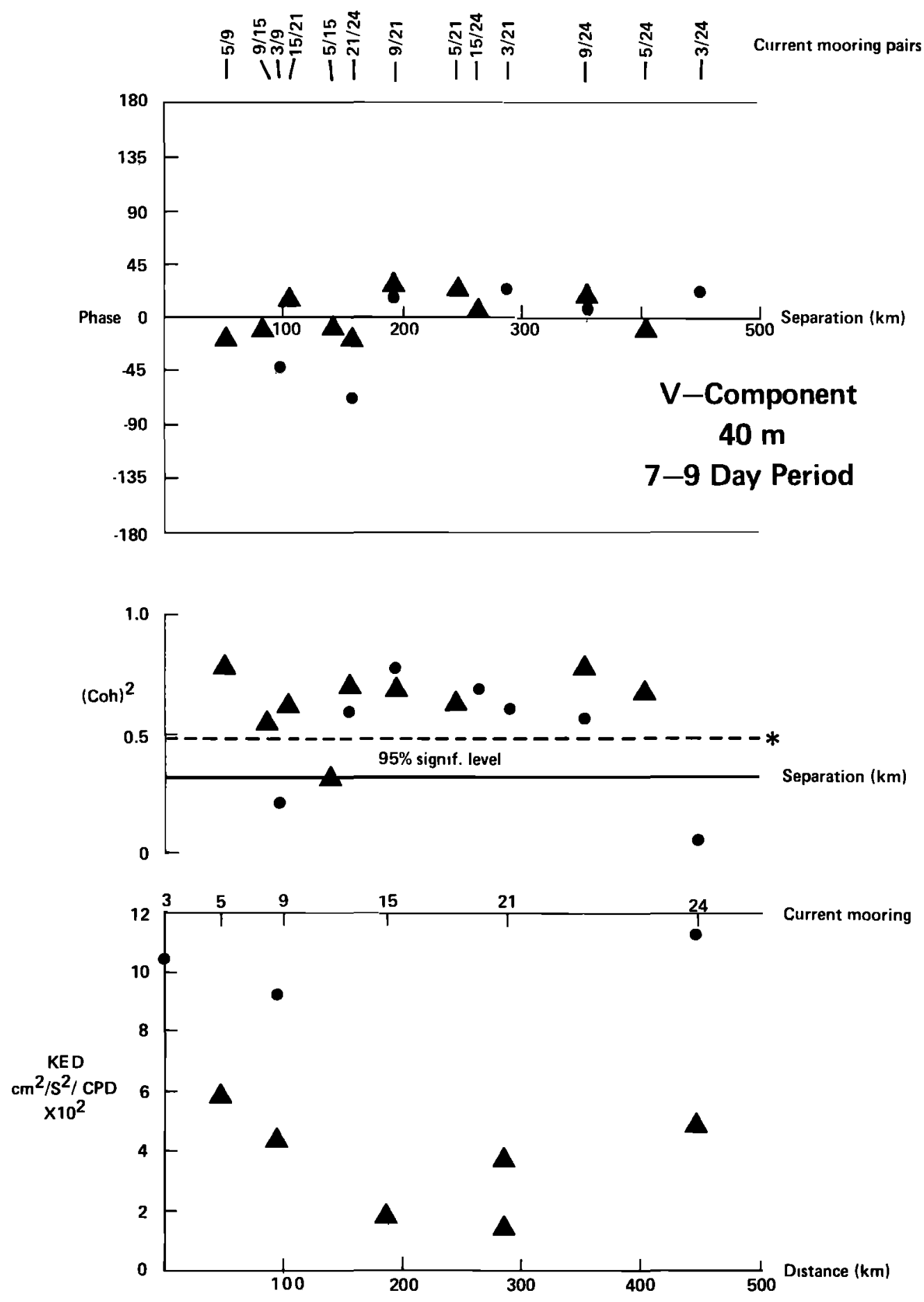

Fig. 16. Along-shelf coherence squared, phase, and energy density for the 40-HLP rotated $v$ component from current meter pairs at 40-m isobath in 7- to 9-day period band; dots are for upper layer, and triangles are for lower layer.

radius of curvature $R$ of $22 \mathrm{~km}$ north of the cold core and $R=\infty$ west of the core where the flow is southward in the warm filament; therefore $d \zeta / d t=-2 \times 10^{-10} \mathrm{~s}^{-2} ; \beta V=5.4$ $\times 10^{-12} \mathrm{~s}^{-2}$, and the vertical velocity at $50 \mathrm{~m}$ is $w=1.4 \times$ $10^{-2} \mathrm{~cm} \mathrm{~s}^{-1}$, which is quite close to the estimate made following rising isotherms. The strength of the vertical velocity depends primarily on the change in curvature vorticity along a streamline. The curvature is cyclonic around the cold core of a frontal eddy which gives a positive (upwelling) vertical velocity.
The strength of the upwelling velocity is about $0.01 \mathrm{~cm} \mathrm{~s}^{-1}$, or $8.6 \mathrm{~m} \mathrm{~d}^{-1}$.

\section{Vorticity Conservation in Frontal Eddies}

The conservation of potential vorticity can be written

$$
\left(\frac{V}{R}-\frac{\partial V}{\partial n}+f\right) N^{2}=\text { const }
$$



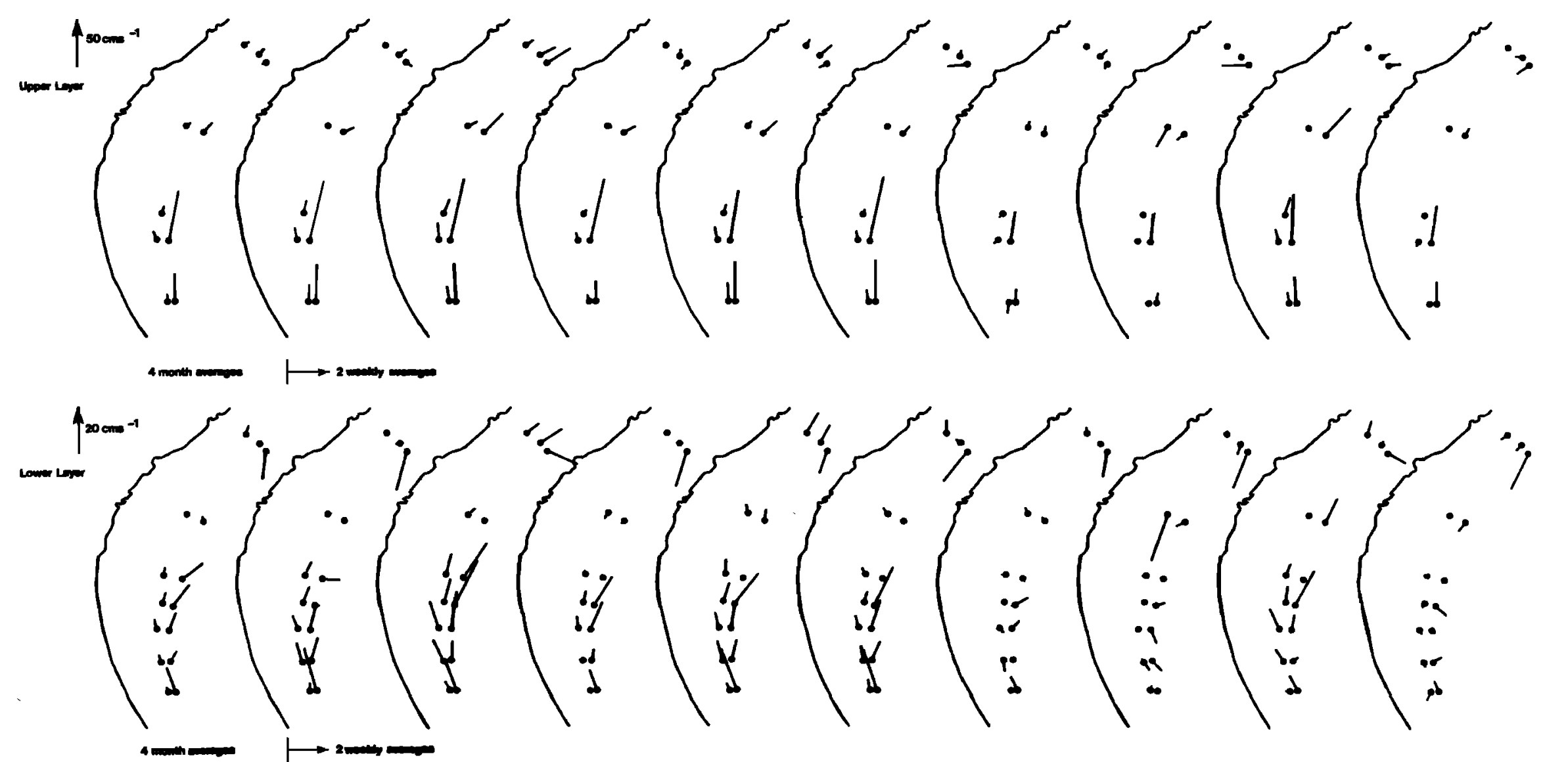

Fig. 17. Mean flows at 40- and 75-m isobaths during GABEX 1. Top panel is for upper layer (scale is $50 \mathrm{~cm} \mathrm{~s}^{-1}$ ), and bottom panel is for lower layer (scale is $20 \mathrm{~cm} \mathrm{~s}^{-1}$ ). First scene is for 4 -month averages; remaining scenes are for consecutive 2 weekly averages. 


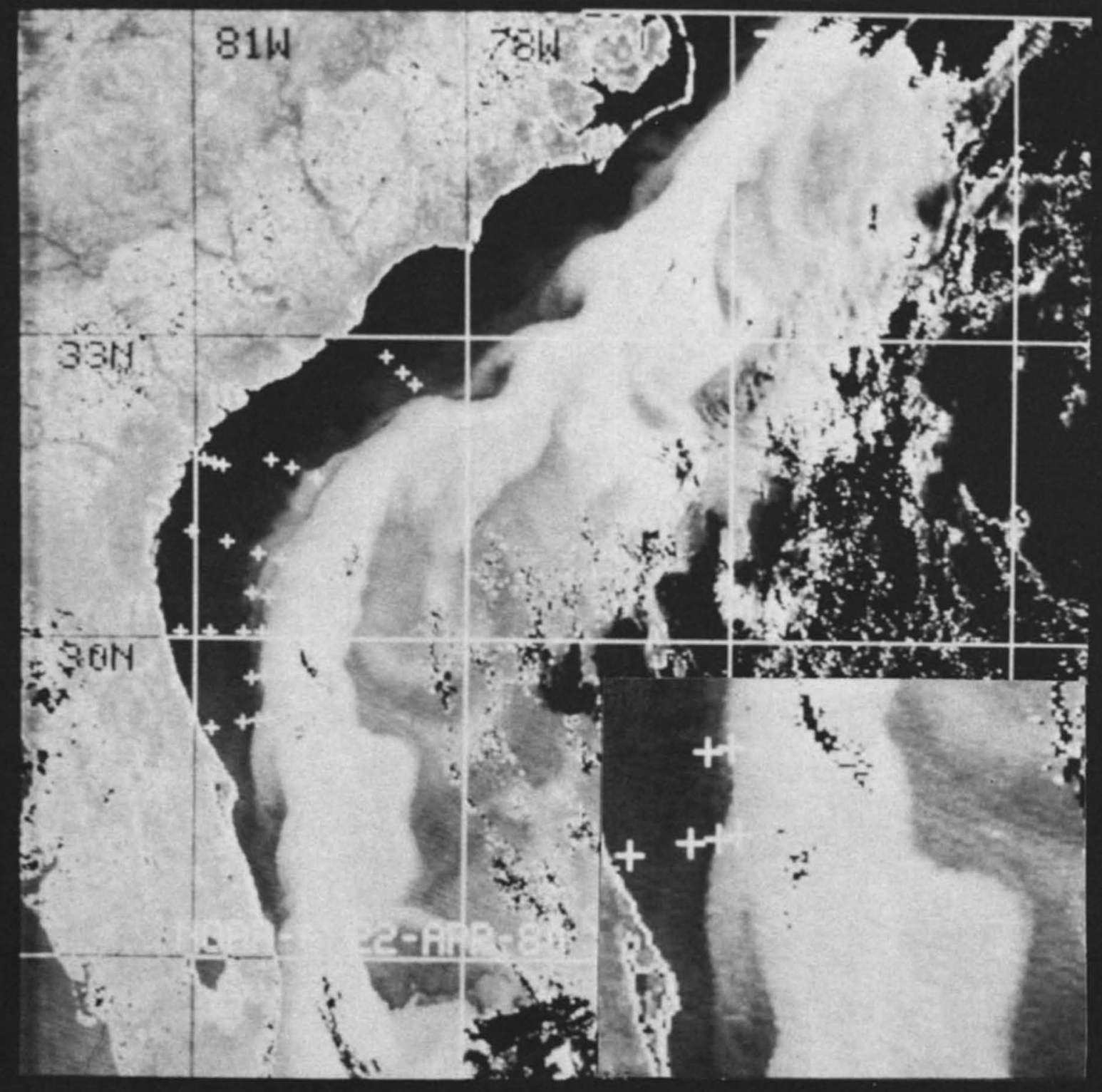

Fig. 18. Satellite VHRR thermal image of the Gulf Stream at 1258 UT on April 22, 1980; crosses are for current mooring locations (prepared by Otis Brown and Bob Evans of the University of Miami). 


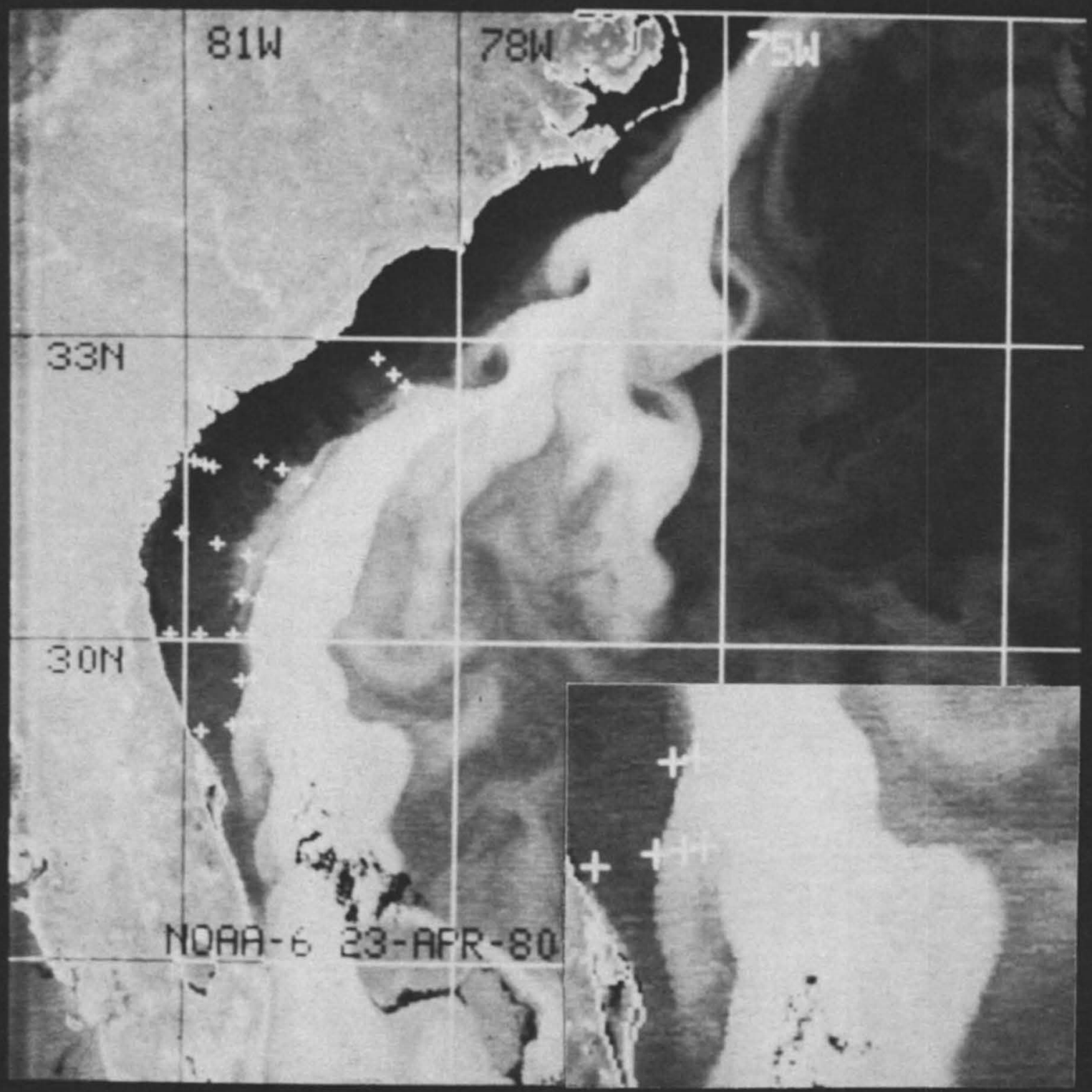




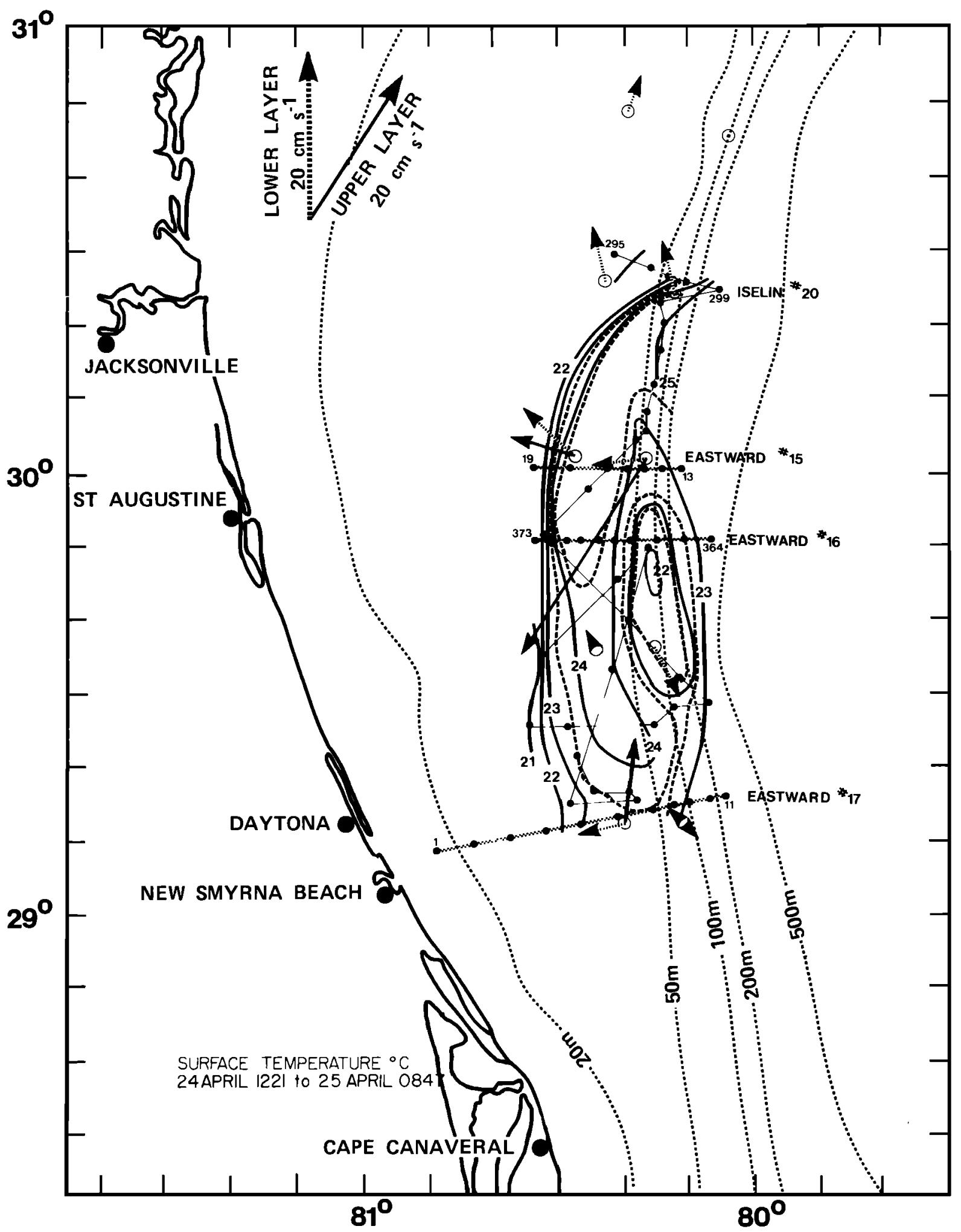

Fig. 20. Ship-measured surface temperature (degrees Centigrade) on April 24 (1221 hours) to April 25 (0847 hours). Straight lines with dots show Iselin ship track and stations. Wavy line and dots show Eastward track and stations. Hydrographic sections are labeled with ship name and endpoint station numbers. Daily averaged currents on April 25 are shown with arrows.

where $\zeta=(V / R)-(\partial V / \partial n)$ is the same as in (2) and the static stability $N^{2}=\left(g / \rho_{0}\right)(\Delta \rho / \Delta z)$ depends on the strength of the pycnocline, with density difference $\Delta \rho$ between two isopycnals separated in the vertical by $\Delta z$. Considering a cyclonic cold core eddy, both the curvature vorticity and shear vorticity will lead to an increase in potential vorticity, which must be compensated for by a decrease in static stability. The shear vorticity produces a positive effect, since in a natural coordinate system $n$ increases to the left of the flow making the shear term negative on the inside (east) of the warm tongue and when combined 


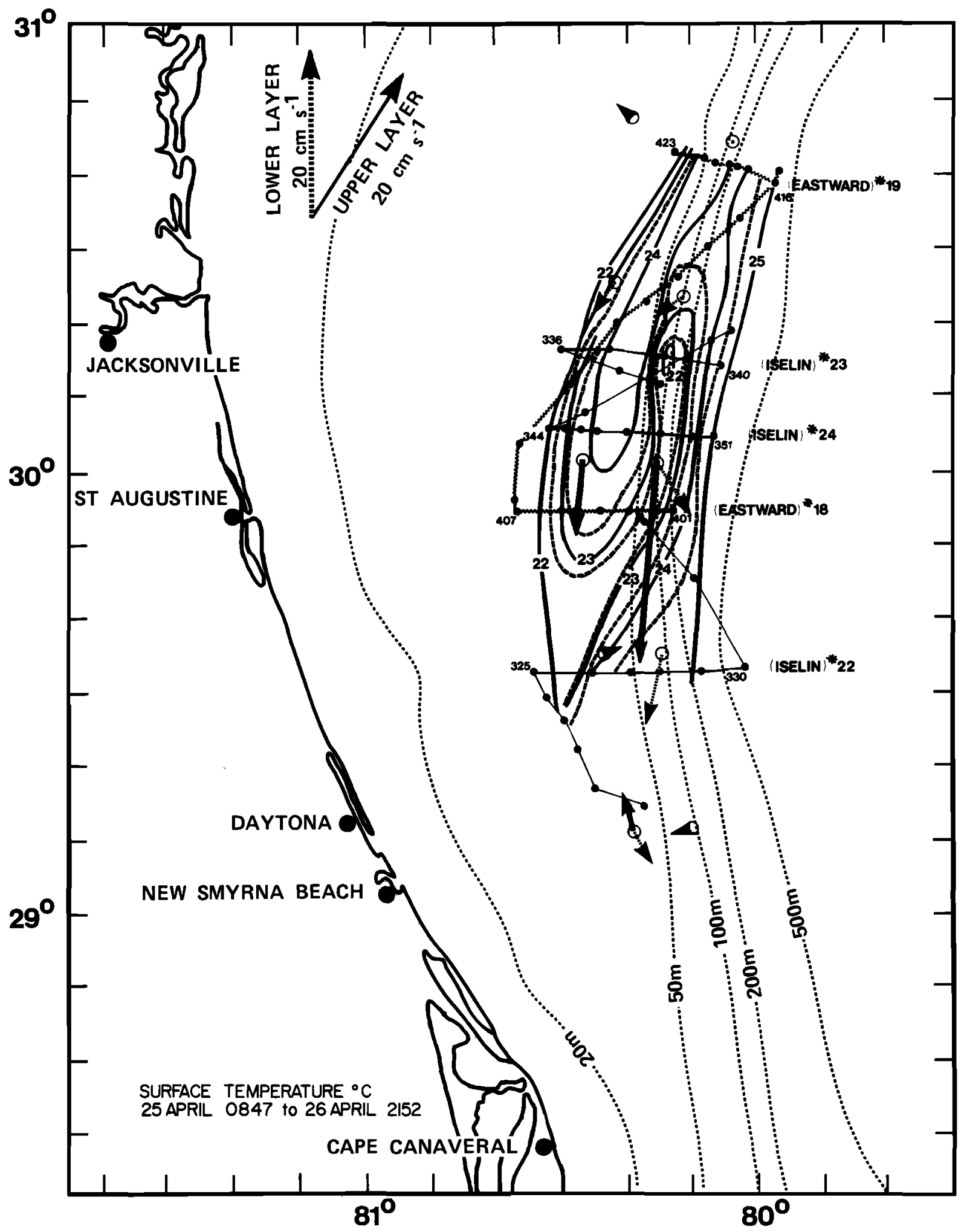

Fig. 21. Ship-measured surface temperature (degrees Centigrade) on April 25 (0847 hours) to April 26 (2152 hours). Straight lines with dots show Iselin ship track and stations. Wavy line and dots show Eastward track and stations. Hydrographic sections are labeled with ship name and endpoint station numbers. Daily averaged currents on April 26 are shown with arrows.

with the minus sign gives a positive effect. On the outside (west) of the warm tongue the shear is positive and so can compensate for the cyclonic curvature by closing up streamlines. Thus in the cold core region, static stability must decrease to compensate the increase in curvature and shear vorticity (changes in planetary vorticity are small). In the cold core of event $8, \mathrm{~N}^{2}$ was observed to decrease by about a factor of 2 compared to estimates in the frontal region north and south of the event. Similar results were found for the 1977 frontal eddy reported on by Lee et al. [1981]. 

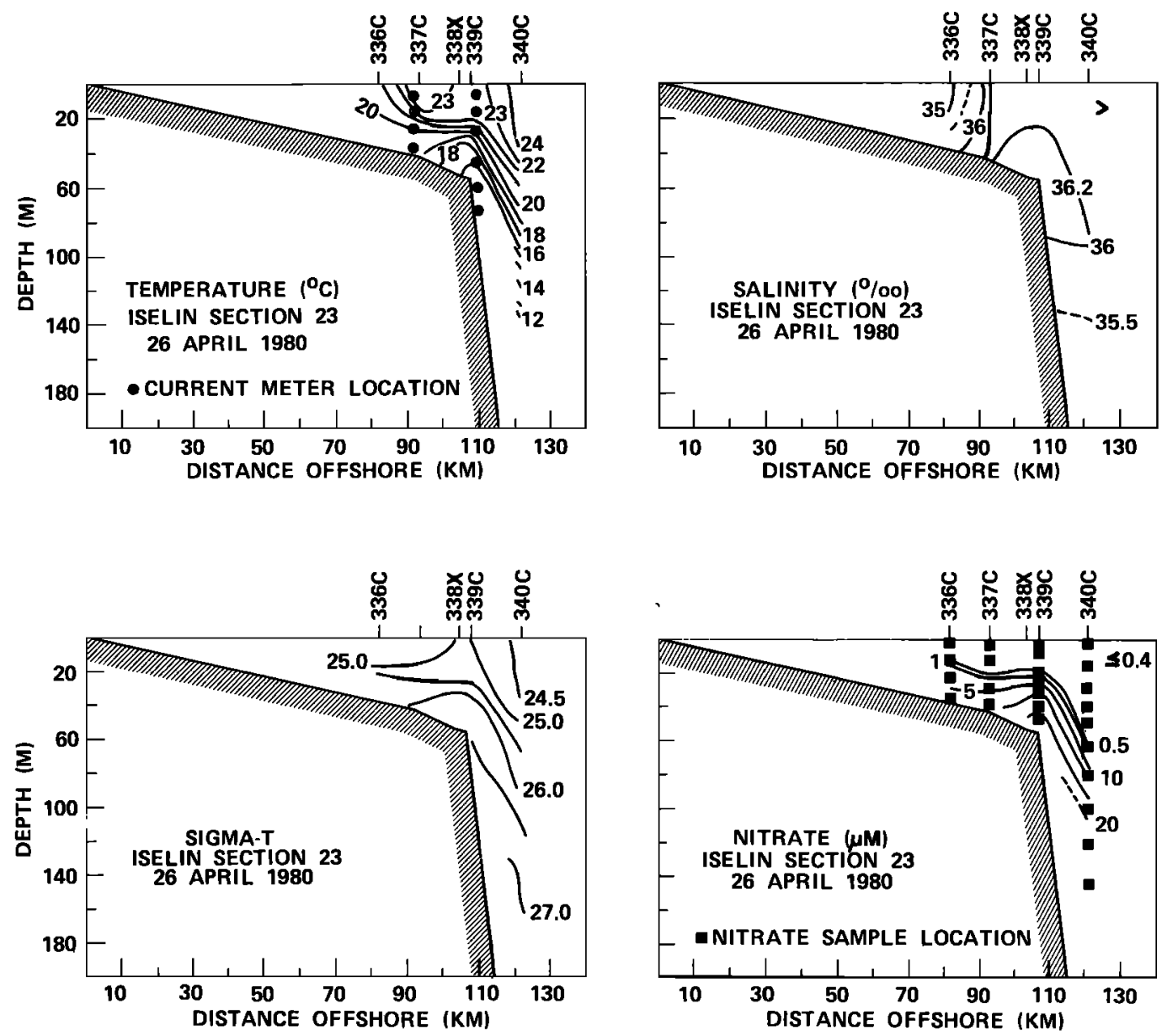

Fig. 22. Temperature (degrees Centigrade), salinity (per mil), density $\left(\sigma_{t}\right)$, and nitrate $(\mu \mathrm{M})$ sections across a Gulf Stream frontal eddy on April 26 (0028 to 0757 hours). Stations are numbered along the top from Iselin section 23 (Figure 21).

\section{Nitrate Flux and Biological Implications}

Previous investigations on the Georgia shelf have shown that upwelling in the cold core of frontal eddies transports deeper Gulf Stream waters with high nutrient concentrations into the euphotic zone which is $<50 \mathrm{~m}$ along the outer shelf [Lee et al., 1981 ; Yoder et al., 1981]. In the absence of eddy-induced upwelling, nitrate concentrations in the outer shelf are usually less than $1.0 \mu \mathrm{mol} l^{-1}$. However, in the cold core of event 8 , nitrate concentrations of $10 \mu \mathrm{mol} l^{-1}$ were observed at a depth of 30 $\mathrm{m}$, and $25 \mathrm{~km}$ shoreward of the shelf break $5 \mu \mathrm{mol} l^{-1}$ were observed in the subsurface intrusion at $30 \mathrm{~m}$ (Figure 21). Lee et al. [1981] used an empirical linear relationship between temperature and nitrate for newly upwelled North Atlantic Central Water and found a net onshore nitrate flux during the passage of a frontal eddy at the shelf break of $-18.6 \mu \mathrm{mol} \mathrm{m} \mathrm{m}^{-2} \mathrm{~s}^{-1}$. Their estimate was made using only two current meters at 72 and $17 \mathrm{~m}$ on the $75-\mathrm{m}$ isobath. The increased resolution available on mooring 10 makes it possible to determine the vertical structure of the nitrate flux and to improve the accuracy of estimates of the vertically averaged flux.

Nitrate time series is computed from the low-frequency temperature $(T)$ at each current meter from the empirical relation [O'Malley et al., 1978]

$$
\left[\mathrm{NO}_{3}\right]=53.0-2.6 \mathrm{~T}
$$

where $\left[\mathrm{NO}_{3}\right]=0$ for $T>20^{\circ} \mathrm{C}$. The net nitrate flux is then computed from

$$
\left\langle u^{\prime} \mathrm{NO}_{3}{ }^{\prime}\right\rangle=\left\langle(u-\tilde{u})\left(\mathrm{NO}_{3}-\tilde{\mathrm{NO}}{ }_{3}\right)\right\rangle
$$

where the angle brackets indicate a time average and $\tilde{u}$ and $\mathrm{NO}_{3}$ are 4-month record averages. Vertical profiles of the nitrate flux averaged over the duration of event 8 (April 23-27) and over the total record length (February 25 to June 21, 1981) are shown in Figure 24. A strong onshore maximum is observed at $45 \mathrm{~m}$ in both the eddy-averaged and total record average profiles. Lee et al. [1981] could not resolve the onshore maximum due to poor vertical resolution, and as a result their vertically averaged flux of $-18.6 \mu \mathrm{mol} \mathrm{m} \mathrm{m}^{-2} \mathrm{~s}^{-1}$ may have greatly underestimated the nitrate transport. The vertically averaged net nitrate flux in event 8 was $-115 \mu \mathrm{mol} \mathrm{m} \mathrm{m}^{-2} \mathrm{~s}^{-1}$ and for the total record average it was $-65 \mu \mathrm{mol} \mathrm{m}^{-2} \mathrm{~s}^{-1}$. Current and temperature records from the shelf break indicate that the frequency of occurrence of eddy-induced upwelling events was approximately 5 per month (Figures 5-8) for the 4-month period. Since the total record averaged nitrate flux was about half the eddy-averaged value and eddies appear to influence the outer shelf about half the time, then it follows that frontal eddies were the dominant contributor to the transport of nitrate across the shelf break.

The total nitrogen transported to the shelf by event 8 can be 

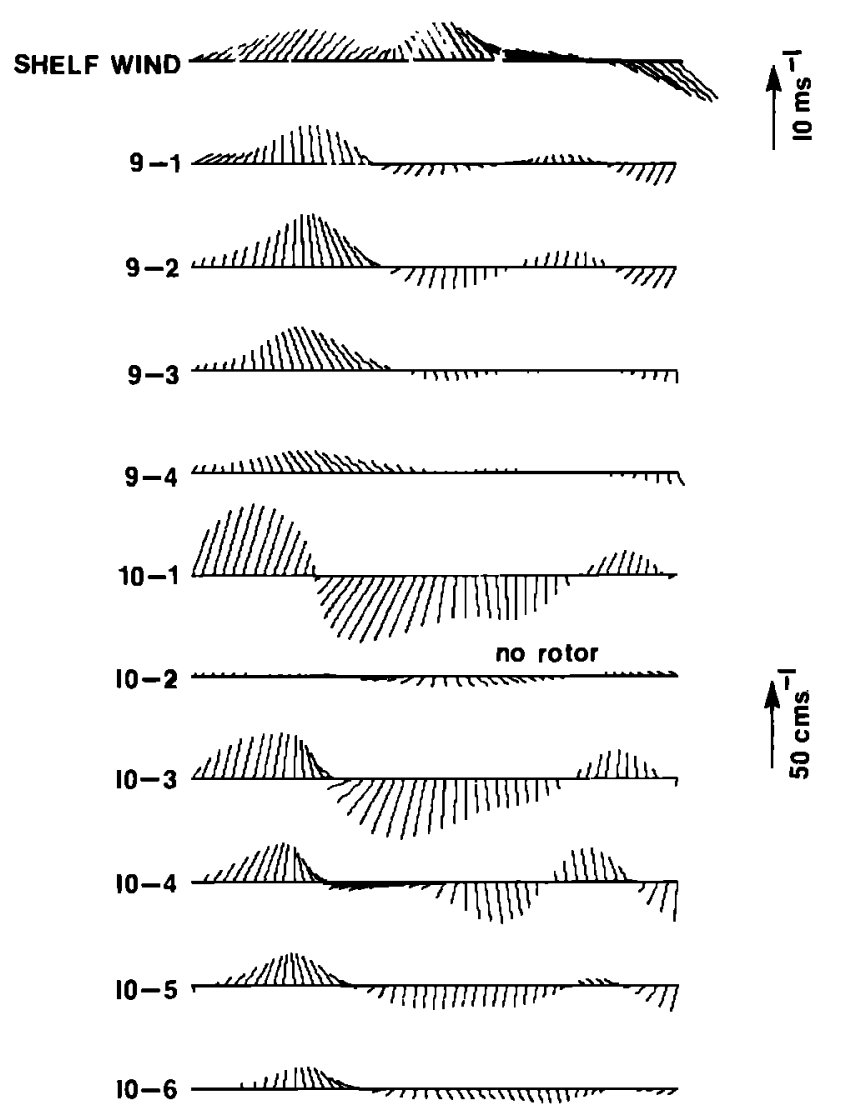

$\begin{array}{lllll}23 & 25 & & 27 & 29 \\ & & \text { APR } & \end{array}$

Fig. 23. Time series of 3-HLP band-pass-filtered wind and current vectors from moorings 9 and 10 during event 8 .

estimated by converting the vertical eddy averaged nitrate flux to a nitrogen flux $\left(Q_{N}\right)$ then finding the total nitrogen $\left(N_{T}\right)$ transported to the shelf by the eddy from

$$
N_{T}=Q_{N} \cdot H \cdot L \cdot T
$$

where $H$ is the height of the shelf break water column $(75 \mathrm{~m}), L$ is the length of the eddy $(130 \mathrm{~km})$, and $T$ is the time it takes the eddy to pass the mooring site or duration (5 days). Using these estimates in (7) with $Q_{N}=1.6 \mathrm{mg} \mathrm{N} \mathrm{m}^{-2} \mathrm{~s}^{-1}$ gives $N_{T}=$ $-6.8 \times 10^{9} \mathrm{~g} \mathrm{~N}$ per eddy or about 7400 tons $\mathrm{N}$ per eddy, which is a factor of 3.5 larger than the value found for the 1977 event [Lee et al., 1981]. Assuming that on the annual average 5 eddies per month occur with an onshore nitrate transport equivalent to the 4-month average $(\sim 1 / 2$ the eddy-averaged transport) gives an annual net nitrogen transport to the shelf by eddy processes of approximately 220,000 tons $\mathrm{N}$ per year. This estimate is about a factor of 8 greater than the estimate of the combined inputs of nitrogen from rivers, atmosphere, and the Gulf Stream made prior to 1977 by Haines [1974]. Yoder et al. [1982] found the potential for carbon production by phytoplankton in the outer shelf from the net onshore nitrogen transport of event 8 was approximately $360 \mathrm{~g} \mathrm{C} \mathrm{m}^{-2} \mathrm{yr}^{-1}$, which is larger than estimates made for the inner shelf (depths $<20 \mathrm{~m}$ ) by Haines and Dunstan [1975] and about $60 \%$ of the primary production estimated for the mouth of a major southeast U.S. river [Thomas, 1966].

\section{Kinematics of Frontal Eddies}

Reynolds stress $\left(\left\langle u^{\prime} v^{\prime}\right\rangle\right)$ averages over the 4-month experiment were generally offshore (positive) along the shelf break, indicating an average offshore transport of northward momentum. The only net onshore transport of momentum observed over the total period was near bottom at the southern mooring (current meter 4-3). Cumulative weekly averages indicate that Reynolds stress estimates became reasonably stable (within $\pm 10 \%$ of the total record average) for averaging periods of 12 to 15 weeks. Maximum offshore momentum transport of about $260 \mathrm{~cm}^{2} \mathrm{~s}^{-2}$ occurred in the upper layer at $30^{\circ} \mathrm{N}(10-1)$ and decreased rapidly with depth. The mean horizontal shear $\partial\langle v\rangle / \partial x$ in the upper layer at this latitude was approximately $2.6 \times 10^{-5} \mathrm{~s}^{-1}$ which gives a horizontal eddy viscosity $A_{H}=$ $-\rho\left\langle u^{\prime} v^{\prime}\right\rangle / \partial\langle v\rangle / \partial x$ of $-8 \times 10^{6} \mathrm{~cm}^{2} \mathrm{~s}^{-1}$. The angle brackets and overbar represent a time average over the record length and the primes denote deviations from the average. Density $\rho$ is taken as $1 \mathrm{~g} \mathrm{~cm}^{-3}$ and $x$ increases in the offshore direction. A negative viscosity was also found in the region of the cyclonic Gulf Stream front off Onslow Bay, North Carolina [Webster, 1961a; Brooks and Bane, 1981], and in the Florida Straits [Schmitz and Niiler, 1969; Brooks and Niiler, 1977] and is believed to indicate a baroclinic instability process where kinetic energy is transferred from the fluctuations to the mean flow [Orlanski, 1969; Orlanski and Cox, 1973]. The rate of net energy transfer can be estimated with current meters at $30^{\circ} \mathrm{N}$ from $\rho\left\langle u^{\prime} v^{\prime}\right\rangle \partial\langle v\rangle / \partial x$ [Webster, 1961b; Schmitz and Niiler, 1969; Brooks and Niiler, 1977]. Brooks and Niiler [1977] found that the net conversion rate of perturbation kinetic energy can be estimated from

$$
\begin{aligned}
\frac{d}{d t}\left\{\frac{1}{2}\left(\left\langle u^{\prime 2}\right\rangle+\left\langle v^{\prime 2}\right\rangle\right)\right\} \\
=-\left\{\left\langle u^{\prime 2}\right\rangle \frac{\partial\langle u\rangle}{\partial x}+\left\langle v^{\prime 2}\right\rangle \frac{\partial\langle v\rangle}{\partial y}+\left\langle u^{\prime} v^{\prime}\right\rangle \frac{\partial\langle v\rangle}{\partial x}\right\}
\end{aligned}
$$

Their estimates for the Florida Current between Miami, Florida, and Bimini, Bahamas, indicated that the total local kinetic energy conversion was dominated by the second term on the right-hand side but for the sectional area average this term was small and the first and third terms were larger and of similar magnitude.

The net local perturbation kinetic energy at the shelf break at $30^{\circ} \mathrm{N}$ can be estimated using current meter data from moorings 4,9 , and 10 . The results for the middle to upper water column and near-bottom layer are given in Table 1. In the upper layer the net local conversion of perturbation kinetic energy was dominated by $\left\langle u^{\prime} v^{\prime}\right\rangle(\partial\langle v\rangle / \partial x)$ which was about an order of magnitude larger than the first and second terms of (8). Nearbottom estimates are 2 orders of magnitude smaller and not significant. The positive net value indicates that there was a net transfer of kinetic energy from the fluctuations to the mean flow at this location, consistent with similar findings in the Gulf Stream cyclonic frontal region off Onslow Bay in the surface layer [Webster, 1961a] and middle to lower water column [Brooks and Bane, 1981]. Brooks and Niiler [1977] also found a region of kinetic energy flux to the mean flow over the total water column in the cyclonic front of the Florida Current off Miami. However, the region was displaced about $8 \mathrm{~km}$ east of the shelf break and energy was transferred to the fluctuations at shelf break. A similar result was found from current meters positioned at the shelf break in the Florida Straits [Lee, 1975; Lee and Mayer, 1977], indicating that the shelf break strip was 


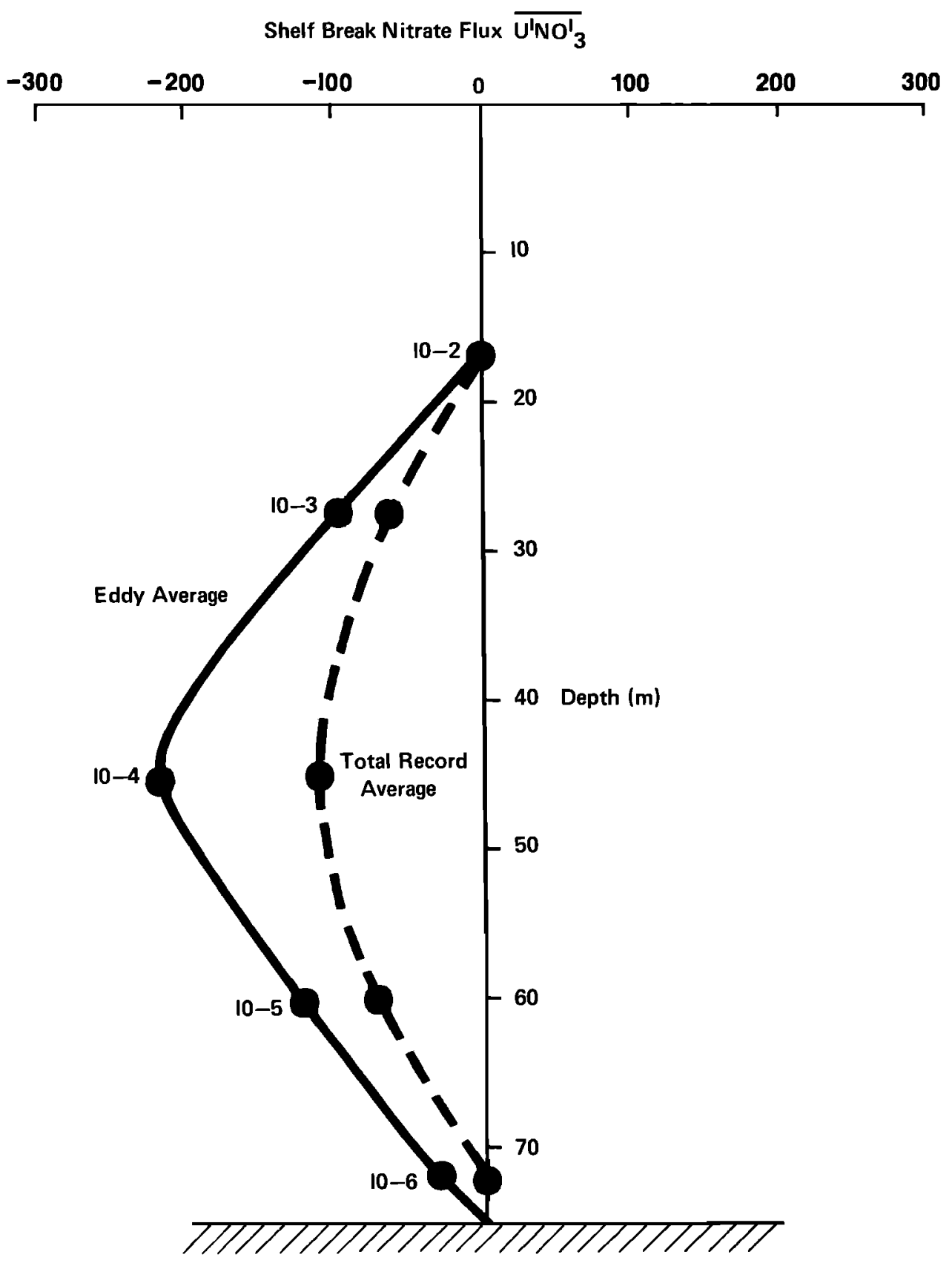

Fig. 24. Shelf break nitrate flux $\left\langle u^{\prime} \mathrm{NO}_{3}{ }^{\prime}\right\rangle\left(\mu \mathrm{mol} \mathrm{m} \mathrm{m}^{-2} \mathrm{~s}^{-1}\right)$ from mooring 10 averaged over eddy event 8 and total 4-month record.

a region of mean energy removial. However, between Cape Canaveral and Savannah the Gulf Stream front follows the shelf break closely and the fluctuations release kinetic energy to the mean flow at about the same rate $\left(58 \times 10^{-4} \mathrm{erg} \mathrm{cm}^{-3} \mathrm{~s}^{-1}\right)$ as was found off Onslow Bay and in the Florida Straits [Brooks and Bane, 1981; Brooks and Niiler, 1977]. The cospectrum of the $u$ versus $v$ velocity components at the shelf break (Figure 10) shows that the positive (offshore) momentum flux was selectively grouped in the 5- to 9-day period band where propagating cold cyclonic perturbations were found to produce coherent $u$ and $v$ fluctuations. Thus the net conversion of perturbation to mean kinetic energy appears to occur throughout the water column at the shelf break and is being driven by fluctuations occurring in the 5- to 9-day period band.

The heat flux $\left\langle u^{\prime} T^{\prime}\right\rangle$ at the shelf break averaged over the 4-month study period was positive within the water column and decreased to small negative values near the bottom. A positive heat flux indicates a net offshore heat transport similar to that found in the Gulf Stream frontal region off Onslow Bay [Oort, 1964; Brooks and Bane, 1981] and in the Florida Straits [Brooks and Niiler, 1977]. Following Brooks and Niiler [1977] the net conversion rate of potential energy can be estimated from

$$
\begin{aligned}
& \frac{d}{d t}\left\{\frac{g}{2}\left\langle\rho^{\prime 2}\right\rangle /\left|\frac{\partial\langle\rho\rangle}{\partial z}\right| \rho_{0}\right\} \\
& =-\left\{g\left\langle u^{\prime} \rho^{\prime}\right\rangle \frac{\partial\langle\rho\rangle}{\partial x}\left|\rho_{0}\right| \frac{\partial\langle\rho\rangle}{\partial z}\left|+g\left\langle v^{\prime} \rho^{\prime}\right\rangle \frac{\partial\langle\rho\rangle}{\partial y}\right| \rho_{0}\left|\frac{\partial\langle\rho\rangle}{\partial z}\right|\right\}
\end{aligned}
$$

Gulf Stream water present in the outer shelf produces a reason- 
TABLE 1. Net Kinetic Energy Exchange Rate at the Shelf Break From February 25 to June 21, 1980

\begin{tabular}{|c|c|c|c|}
\hline Quantity & Units & $\begin{array}{l}\text { Net Value } \\
\text { Upper Layer } \\
\text { (Depths of } \\
27-45 \mathrm{~m} \text { ) }\end{array}$ & $\begin{array}{c}\text { Net Value } \\
\text { LowerLayer } \\
\text { (3 m Above } \\
\text { Bottom) }\end{array}$ \\
\hline $\begin{array}{l}\left\langle u^{\prime 2}\right\rangle \\
\left\langle v^{\prime 2}\right\rangle \\
\left\langle u^{\prime} v^{\prime}\right\rangle\end{array}$ & $\begin{array}{l}\mathrm{cm}^{2} \mathrm{~s}^{-2} \\
\mathrm{~cm}^{2} \mathrm{~s}^{-2} \\
\mathrm{~cm}^{2} \mathrm{~s}^{-2}\end{array}$ & $\begin{array}{r}106 \\
1198 \\
194\end{array}$ & $\begin{array}{r}34 \\
184 \\
13\end{array}$ \\
\hline$\frac{\partial\langle u\rangle}{\partial x}$ & $\mathrm{~s}^{-1}$ & $4.2 \times 10^{-6}$ & $2.0 \times 10^{-6}$ \\
\hline$\frac{\partial\langle v\rangle}{\partial y}$ & $\mathrm{~s}^{-1}$ & $2.5 \times 10^{-7}$ & $-3.1 \times 10^{-7}$ \\
\hline$\frac{\partial\langle v\rangle}{\partial x}$ & $s^{-1}$ & $2.6 \times 10^{-5}$ & $2.0 \times 10^{-6}$ \\
\hline$\left\langle\rho u^{\prime 2}\right\rangle \frac{\partial\langle u\rangle}{\partial x}$ & $\operatorname{ergs~} \mathrm{cm}^{-3} \mathrm{~s}^{-1}$ & $4.4 \times 10^{-4}$ & $0.7 \times 10^{-4}$ \\
\hline$\left\langle\rho v^{\prime 2}\right\rangle \frac{\partial(v)}{\partial y}$ & ergs $\mathrm{cm}^{-3} \mathrm{~s}^{-1}$ & $3.0 \times 10^{-4}$ & $-0.6 \times 10^{-4}$ \\
\hline$\left\langle\rho u^{\prime} v^{\prime}\right\rangle \frac{\partial\langle v\rangle}{\partial x}$ & $\operatorname{ergs~} \mathrm{cm}^{-3} \mathrm{~s}^{-1}$ & $50.4 \times 10^{-4}$ & $0.3 \times 10^{-4}$ \\
\hline$\left\langle\rho u^{\prime 2}\right\rangle \frac{\partial\langle u\rangle}{\partial x}+\left\langle\rho v^{\prime 2}\right\rangle \frac{\partial\langle v\rangle}{\partial y}+\left\langle\rho u^{\prime} v^{\prime}\right\rangle \frac{\partial\langle v\rangle}{\partial x}$ & ergs $\mathrm{cm}^{-3} \mathrm{~s}^{-1}$ & $57.8 \times 10^{-4}$ & $0.4 \times 10^{-4}$ \\
\hline
\end{tabular}

ably constant $T-S$ relationship [Lee et al., 1981] that is used with temperature from current meters on moorings 4,9 , and 10 to evaluate rates of potential energy conversion in the same manner as kinetic energy conversion. The results are presented in Table 2. There was a net transfer of perturbation potential energy from the fluctuations to the mean at the shelf break that can be largely accounted for by $g\left\langle u^{\prime} \rho^{\prime}\right\rangle(\partial\langle\rho\rangle / \partial x) /|\partial\langle\rho\rangle / \partial z|$. The cospectrum of $u$ versus $T$ (Figure 10 ) is quite similar to the cospectrum of $u$ versus $v$ and indicates that coherent current and temperature fluctuations occurring in the 5- to 9-day period band were the cause of the local generation of mean potential energy at the shelf break.

\section{Conclusions}

Low-frequency current and temperature variability along the outer shelf of the southeastern U.S. continental shelf appears to restlt from a combination of wind forcing and interaction with the Gulf Stream. Subtidal current and temperature fluctuations along the shelf break result primarily from propagating disturbances in the Gulf Stream front. Along the 40-m isobath, lowfrequency variability appears to be a mixed response to wind and Gulf Stream forcing with nonpropagating wind effects more clearly observable.

Low-frequency current and temperature variability and fluxes of momentum, heat, and nutrients at the shelf break result largely from northward propagating Gulf Stream frontal disturbances. Current meter, hydrographic, and satellite observations indicate that these disturbances are cold cyclonic eddies embedded in the Gulf Stream front. These features were observed to propagate to the north at speeds of 50 to $70 \mathrm{~cm} \mathrm{~s}^{-1}$ and produce coherent fluctuations of cross-shelf and alongshelf velocity components and temperature throughout the water column in the 5- to 9-day period band over along-shelf coherence scales of $100 \mathrm{~km}$. The frontal eddy signature in along- shelf pairs of current meters at the shelf break consists of a propagating cyclonic perturbation of the northward mean

TABLE 2. Net Potential Energy Exchange Rate at the Shelf Break From February 25 to June 21, 1980

\begin{tabular}{llc}
\hline \multicolumn{1}{c}{ Quantity } & \multicolumn{1}{c}{$\begin{array}{c}\text { Net Value } \\
\text { Units }\end{array}$} & $\begin{array}{c}\text { Upper Layer } \\
\text { (Depths of 27-45 m) }\end{array}$ \\
\hline$\left\langle u^{\prime} \rho^{\prime}\right\rangle$ \\
$\left\langle v^{\prime} \rho^{\prime}\right\rangle$ \\
$\frac{\partial\langle\rho\rangle}{\partial x}$ \\
$\frac{\partial\langle\rho\rangle}{\partial y}$ \\
$\left|\frac{\partial\langle\rho\rangle}{\partial z}\right|$ \\
$g\left\langle u^{\prime} \rho^{\prime}\right\rangle \frac{\partial\langle\rho\rangle}{\partial x} /\left|\frac{\partial\langle\rho\rangle}{\partial z}\right|$ & $\mathrm{g} \mathrm{cm}^{-2} \mathrm{~s}^{-1}$ & $-1.7 \times 10^{-3}$ \\
$\mathrm{~g} \mathrm{~cm}^{-2} \mathrm{~s}^{-1}$ & $-1.2 \times 10^{-2}$ \\
$\mathrm{~g} \mathrm{~cm}^{-4}$ & $-3.1 \times 10^{-10}$ \\
$g\left\langle v^{\prime} \rho^{\prime}\right\rangle \frac{\partial\langle\rho\rangle}{\partial y} /\left|\frac{\partial\langle\rho\rangle}{\partial z}\right|$ & $\mathrm{g} \mathrm{cm}^{-4}$ & $-0.1 \times 10^{-10}$ \\
$g\left\langle u^{\prime} \rho^{\prime}\right\rangle \frac{\partial\langle\rho\rangle}{\partial x} /\left|\frac{\partial \rho}{\partial z}\right|+g\left\langle v^{\prime} \rho^{\prime}\right\rangle \frac{\partial\langle\rho\rangle}{\partial y} /\left|\frac{\partial\langle\rho\rangle}{\partial z}\right|$ & $\mathrm{g} \mathrm{cm}^{-4}$ & $2.7 \times 10^{-7}$ \\
\end{tabular}


flow coupled to a sharp drop in temperature. The response is observed throughout the water column with larger temperature fluctuations usually occurring in the lower layer. A cyclonic current reversal may occur on the western side of an eddy if the eddy velocity is larger than the northward mean flow.

Eddy SST signature consists of the 'shingle' pattern [Von Arx et al., 1955] which develops as a warm filament of nearsurface Gulf Stream water 10 to $15 \mathrm{~m}$ deep is pulled out of the front and wraps around a cold core, presumably by the cyclonic eddy circulation in much the same manner as 'streamers' associated with warm and cold core rings [Vukovich and Grissman, 1978]. The eddy circulation appears to be in quasigeostrophic equilibrium with uplifted density surfaces in the cold core. There was no indication in current and temperature records of anticyclonic circulation in the warm filaments as was suggested by Chew [1981]. The movement of a warm filament with anticyclonic circulation should produce a propagating anticyclonic perturbation of the northward mean flow coupled to an increase in temperature, which was not observed at the outer shelf current meter sites.

The formation process of frontal eddies is not well understood. The shingle signature observed in satellite imagery appears to be connected to growing wavelike meanders of the Gulf Stream front [Legeckis, 1975; Stumpf and Rao, 1975; Legeckis, 1979]. Theoretical investigations predict that both barotropic [Niiler and Mysak, 1971] and baroclinic [Orlanski, 1969; Orlanski and Cox, 1973] instabilities can exist in the frontal region with wave properties for the fastest growing waves that match reasonably well with the satellite observations, i.e., wavelengths of 100 to $200 \mathrm{~km}$ and periods $\approx 10$ days. Our observations show that cyclonic eddies travel in conjunction with the offshore meander portion of the waves. Similar findings were reported from the Florida Straits [Lee and Mayer, 1977] and off Onslow Bay, North Carolina [Bane et al., 1981]. Frontal eddies do not appear to be directly or simply connected to wind forcing. However, wind events may act to trigger a frontal instability which could grow into an eddy.

Frontal eddies are short-lived phenomena. They can form in only a few days and possibly dissipate just as fast. Satellite imagery suggests that the total cycle takes place in 1 to 3 weeks. The eddy process appears to be an important component in the Gulf Stream energy balance. Between New Smyrna Beach, Florida, and Savannah, Georgia, frontal eddies transport momentum and heat to the Gulf Stream as part of the process of transferring both perturbation kinetic and potential energy to the mean flow. Eddy production of mean energy in the area of the current meter array suggests an upstream formation region, possibly where the shelf widens north of Jupiter, Florida, as the Gulf Stream leaves the Florida Straits. Dissipation appears to occur through a rapid elongation process brought about by the large horizontal shear across the Gulf Stream front. Dissipation of this type is consistent with the estimated energy transfer and should cause a strengthening of the front. A similar process may occur off Onslow Bay, North Carolina. The kinematic and dynamic properties of the enlarged frontal disturbances that form downstream of the Charleston Bump appear to be consistent with the eddies we observed upstream of the bump [Bane et al., 1981; Brooks and Bane, 1981]. Occasionally shingles are observed in satellite imagery that maintain recognizable integrity as they propagate from the upstream to downstream region with considerable enlargement occurring downstream of the bump [Lee et al., 1981]. However, positive identification of events in satellite imagery requires about 1 week of consecutive cloud-free days, which rarely occur. Our shelf break current meter records also indicate that frontal disturbances can maintain continuity between regions and produce larger fluctuations downstream of the bump.

Frontal eddies are observed to have considerable influence on primary production in the outer shelf. Upwelling in the cold core, together with onshore flow in the cyclonic circulation, transports deeper nutrient-enriched Gulf Stream waters into the euphotic zone for phytoplankton uptake. Upwelling velocities are estimated at $8.5 \mathrm{~m} \mathrm{~d}^{-1}$. Rapid utilization of newly upwelled nutrients results in elongated patches of high chlorophyll that propagate with the cold core and have similar dimensions [Yoder et al., 1981]. Since the demise of frontal eddies appears to occur as a shear-induced dissipation process rather than a collapse of isopycnal surfaces, the upwelled nutrients should remain in the outer shelf, possibly causing chlorophyll bands in the Gulf Stream front. Estimates of nitrate flux from current meter records show a net onshore transport of -115 mol m$~^{-2} \mathrm{~s}^{-1}$ across the shelf break during the passage of a frontal eddy, which was approximately a factor of 2 larger than the 4-month average transport. Current meter records indicate that frontal eddies occurred at a frequency of about $5 /$ month and were the main contributor to the nitrate flux. The annual input of new nitrogen to the shelf by frontal eddies is estimated at $-62.6 \mathrm{~g} \mathrm{~N} \mathrm{~m}^{-2} \mathrm{yr}^{-1}$. This new nitrogen has a potential for carbon production by primary producers of $360 \mathrm{~g} \mathrm{C} \mathrm{m}^{-2} \mathrm{yr}^{-1}$ which is about a factor of 2 higher than estimates for the inner shelf by Haines and Dunstan [1975] and equivalent to estimates by Thomas [1966] for the mouth of the Altamaha River.

Acknowledgments. We thank the crew of the R/V Columbus Iselin for their aid in field operations. Special thanks are extended to Phil Bedard, Ted Tankard, Paula Anderson, Nedra Chalker, Jere Green, Robert Guest, Paul Galbreath, and Gary Rosiello for technical assistance. We appreciate discussions with Don Olson, Chris Mooers, Claes Rooth, John Woods, and Jim Yoder. We particularly wish to acknowledge the help of Steve Baig of NOAA-NESS, Miami, who transmitted satellite images to the ship, and the U.S. Coast Guard, especially Joe Deaver, who participated in the study in providing SST maps with Coast Guard aircraft. We thank Otis Brown and Bob Evans for supplying the satellite thermal images shown in Figures 18 and 19. This research was supported by the Department of Energy under contracts EY-76-S-05-5163 and EY-76-S-09-0889 and the Bureau of Land Management under prime contract AAT851-CT1-25 to Science Applications, Inc., of Raleigh, North Carolina, subcontract 11-820294-11.

\section{REFERENCES}

Arthur, R. S., On the calculation of vertical motion in eastern boundary currents from determinations of horizontal motion, J. Geophys. Res., 70, 2799-2803, 1965.

Atkinson, L. P., T. N. Lee, J. O. Blanton, and W. S. Chandler, Climatology of the southeastern United States continental shelf waters, $J$. Geophys. Res., this issue.

Bane, J. M., Initial observations of the subsurface structure and shortterm variability of the seaward deflection of the Gulf Stream off Charleston, South Carolina, J. Geophys. Res., this issue.

Bane, J. M., Jr., and D. A. Brooks, Gulf Stream meanders along the continental margin from the Florida Straits to Cape Hatteras, Geophys. Res. Lett., 6, 280-282, 1979.

Bane, J. M., Jr., D. A. Brooks, and K. R. Lorenson, Synoptic observations of the three-dimensional structure, propagation, and evolution of Gulf Stream meanders along the Carolina continental margin, $J$. Geophys. Res., in press, 1981.

Beardsley, R. C., and B. Butman, Circulation on the New England continental shelf: Response to strong winter storms, Geophys. Res. Lett., 1, 181-184, 1974.

Blanton, J. O., The transport of freshwater off a multi-inlet coastline in Modeling of Estuaries and Wetland Processes, edited by P. Hamilton and K. B. MacDonald, pp. 49-64, Plenum, New York, 1980. 
Brooks, D. A., and J. M. Bane, Jr., Gulf Stream deflection by a bottom feature off Charleston, South Carolina, Science, 201, 1225-1226, 1978.

Brooks, D. A., and J. M. Bane, Jr., Gulf Stream fluctuations and meanders over the Onslow Bay upper continental slope, J. Phys. Oceanogr., 11(2), 247-256, 1981.

Brooks, I. H., and P. P. Niiler, Energetics of the Florida Current, $J$. Mar. Res., 35, 162-191, 1977.

Bumpus, D. F., A description of the circulation on the continental shelf of the east coast of the United States, Prog. Oceanogr., 6, 111-156, 1973.

Chew, F., Spin-off eddies and an hypothesis, Deep Sea Res., 28, 329391, 1981.

Dunstan, W. M., and L. P. Atkinson, Sources of new nitrogen for the South Atlantic Bight, Estuarine Processes, 1, 69-78, 1976.

Haines, E. B., Processes affecting production in Georgia coastal waters, Ph.D. dissertation, 118 pp., Duke Univ., Durham, N. C., 1974.

Haines, E. B., and W. M. Dunstan, The distribution and relation of particulate organic material and primary productivity in the Georgia Bight, 1973-1974, Estuarine Coastal Mar. Sci., 3, 431-441, 1975.

Hickey, B. M., and P. Hamilton, A spin-up model as a diagnostic tool for interpretation of current and density measurements on the continental shelf of the Pacific northwest, J. Phys. Oceanogr., 1O(1), 12-24, 1980.

Klinck, J. M., L. J. Pietrafesa, and G. S. Janowitz, Continental shelf circulation induced by a moving, localized wind stress, J. Phys. Oceanogr., 11, 836-848, 1981.

Leaman, K. D., T. N. Lee, and R. D. Findley, Performance of an experimental Aanderaa current meter modified for near-surface measurements, submitted to Mar. Technol. Soc. J., 1982.

Lee, T. N., Florida Current spin-off eddies, Deep Sea Res., 22, 753-765, 1975.

Lee, T. N., and D. A. Brooks, Initial observations of current, temperature and coastal sea level response to atmospheric and Gulf Stream forcing on the Georgia shelf, Geophys. Res. Lett., 6, 321-324, 1979.

Lee, T. N., and D. Mayer, Low frequency current variability and spin-off eddies on the shelf off southeast Florida, J. Mar. Res., 35, 193-220, 1977.

Lee, T. N., L. P. Atkinson, and R. Legeckis, Observations of a Gulf Stream frontal eddy on the Georgia continental shelf, April 1977, Deep Sea Res., 28(4), 347-378, 1981.

Legeckis, R., Applications of synchronous meteorological satellite data to the study of time dependent sea surface temperature changes along the boundary of the Gulf Stream, Geophys. Res. Lett., 2, 435-438, 1975.

Legeckis, R., Satellite observations of the influence of bottom topography on the seaward deflection of the Gulf Stream off Charleston, South Carolina, J. Phys. Oceanogr., 9, 483-497, 1979.
Niiler, P. P., and L. A. Mysak, Barotropic waves along an eastern continental shelf, Geophys. Astrophys. Fluid Dyn., 2, 273-278, 1971.

O'Malley, P. G., L. P. Atkinson, J. J. Singer, W. S. Chandler, and T. N. Lee, Hydrographic observations in the Georgia Bight (April 1977), Tech. Rep. 78-5, 208 pp., Ga. Mar. Sci. Center, Atlanta, 1978.

Oort, A. H., Computations of eddy heat and density transports across the Gulf Stream, Tellus, 16, 55-63, 1964.

Orlanski, I., The influence of bottom topography on the stability of jets in a baroclinic fluid, J. Atmos. Sci., 26, 1216-1232, 1969.

Orlanski, I., and M. D. Cox, Baroclinic instability in ocean currents, Geophys. Astrophys. Fluid Dynamics, 4, 297-332, 1973.

Pietrafesa, L. J., L. P. Atkinson, and J. O. Blanton, Evidence for deflection of the Gulf Stream by the Charleston Rise, Gulf Stream, IV(9), 3-7, 1978.

Schmitz, W. J., Jr., and P. P. Niiler, A note on the kinetic energy exchange between fluctuations and mean flow in the surface layer of the Florida Current, Tellus, 21, 814-819, 1969.

Scott, J. T., and G. T. Csanady, Nearshore currents off Long Island, J. Geophys. Res., 81, 5401-5409, 1976.

Singer, J. J., L. Atkinson, J. O. Blanton, and Y. A. Yoder, Cape Romain and the Charleston Bump: Historical and recent hydrographical observations, J. Geophys. Res., this issue.

Stumpf, H. G., and P. K. Rao, Evolution of Gulf Stream eddies as seen in satellite infrared imagery, J. Phys. Oceanogr., S, 388-393, 1975.

Thomas, J. P., Influence of the Altamaha River on primary production beyond the mouth of the river, M.S. thesis, 88 pp., Univ. of Ga., Atlanta, 1966.

Von Arx, W. S., D. F. Bumpus, and W. S. Richardson, On the fine structure of the Gulf Stream front, Deep Sea Res., 3, 46-65, 1955.

Vukovich, F. M., and B. W. Grissman, Further studies of a cold eddy on the eastern side of the Gulf Stream using satellite data and ship data, J. Phys. Oceanogr., 8, 838-843, 1978.

Webster, F. A., A description of Gulf Stream meanders off Onslow Bay, Deep Sea Res., 8, 130-143, 1961 .

Webster, F. A., The effect of meanders on the kinetic energy balance of the Gulf Stream, Tellus, 13, 391-401, 1961b.

Yoder, J. A., L. P. Atkinson, T. N. Lee, H. H. Kim, and C. K. McClain, Role of Gulf Stream frontal eddies in forming phytoplankton patches on the outer southeastern shelf, Limnol. Oceanogr., 26, 11031110,1981 .

Yoder, J. A., L. P. Atkinson, S. S. Bishop, E. Hofmann, and T. N. Lee, 1982: Effect of upwelling on phytoplankton productivity and bloom dynamics on the outer southeast U.S. continental shelf, submitted to Deep Sea Res., 1982.

(Received March 9, 1982 revised June 21, 1982; accepted June 21, 1982.) 